\title{
An Approach for Asynchronous Awareness Support in Collaborative Non-Linear Storytelling
}

\author{
Jana Schumann ${ }^{1}$, Tanja Buttler ${ }^{2} \&$ Stephan Lukosch ${ }^{2}$ \\ ${ }^{1}$ Faculty of Computer Science, Department of Simulation and Graphics, University of Magdeburg, \\ Universitätsplatz 2, 39106 Magdeburg, Germany (E-mail: jana.schumann@st.ovgu.de); ${ }^{2}$ Faculty of \\ Technology Policy and Management, Delft University of Technology, P.O. box 5015, 2600 GA Delft, \\ The Netherlands (Phone:+31-15-27822565; Fax:+31-15-2783429; E-mail: t.buttler@tudelft.nl; \\ Phone:+31-15-2783403; Fax:+31-15-2783429; E-mail: s.g.lukosch@tudelft.nl)
}

\begin{abstract}
Workspace awareness support is mandatory for group support systems. It allows users not only to follow actions of others, but to understand and respond to any changes others make to the workspace. In this paper, we present a novel approach for asynchronous awareness support by offering different filters to retrieve relevant awareness information and visualizing the evolution of the shared artifact. We illustrate our approach with a tool for collaborative non-linear storytelling in which users can jointly create a story graph of interconnected audio files. Such a story graph is an example for a nonlinear story. We describe the development of a prototype that visualizes how the collaborative story has evolved over time. We evaluate our approach for asynchronous awareness support in an experiment with 40 participants exploring story graphs of different complexity. The evaluation results show that our visualization approach helps group members to assess who has modified the shared story, how it was modified, what exactly has been modified, and when it has been modified.
\end{abstract}

Key words: asynchronous workspace awareness, collaborative storytelling, information visualization, traceability

\section{Introduction}

Collaboration has become a critical skill for organizations (Nunamaker et al. 2009). As products and services are becoming increasingly complex, no individual has the skills to design, develop, and deliver these alone. As a result, shared artifacts are often created over time. Typical examples are co-authoring of papers, iterating designs, negotiating plans or decision-making. Often the collaboration occurs in face-to-face meetings or distributed meetings at the same time. However, there are also various examples when such synchronous interaction is not possible (Tam and Greenberg 2006):

- Users pass the joint artifact back and forth for comments and revisions.

- Users work on the artifact as time and opportunities arise, without explicitly coordinating this with the other participants. 
- A group switches between synchronous co-located work and asynchronous distributed work, e.g. by starting the project in a face-to-face meeting but continuing asynchronously once the meeting is over.

Collaboration in general includes numerous challenges. On a process level free riding, dominance, group think, or hidden agendas are a few phenomena in group work that make it a non-straightforward effort (Nunamaker et al. 1997). On a group level it is essential to create a shared understanding, define rules for decision-making, and facilitate interaction in such a way that effective collaboration becomes possible (Lu et al. 2007; Piirainen et al. 2010). When considering asynchronous collaboration, as described in the examples above, the major challenge is to create shared understanding. This is often due to missing awareness support. Users have difficulties to understand recent changes as they are used to tell other users what they have done or by inspecting the artifact and identifying the changes manually. Tam and Greenberg (Tam and Greenberg 2006) conclude that in case of missing asynchronous awareness support collaboration gets out of control and missed changes can ravage the whole collaborative process unintentionally.

We have observed the need for asynchronous awareness support within a tool for collaborative audio-based storytelling (Lukosch et al. 2011). Stories convey a sequence of events and their circumstances, communicated verbally or written (Valle et al. 2003). They are an ancient way to exchange experiences (Totzke 2005). Verbally told stories convey personal perceptions, cultural aspects, good and bad practices, and speculations (Ochs and Capps 2001; Orr 1996; Bruner 1991). They are placed into context in order to improve the understanding of the audience (Bruner 1991). In oral communication stories can create shared understanding (Weick et al. 2005) by exploring different story lines accommodating facts, observations, background knowledge, and expectations with regard to human behavior. Stories are told at home between family members, see e.g. (Ochs and Capps 2001), but also in the workplace. Here, technicians (Orr 1996) and project managers (Buttler et al. 2011) have been observed to exchange stories to convey experiences and share encountered problems and their solutions.

Collaborative storytelling aims at the development of a common understanding within a group through coordinated narrating activities to make implicit knowledge explicit (Lukosch et al. 2011). In text-based approaches to collaborative storytelling a contributor is responsible for entering the content of the story. Contributors share their own experience in the form of events and circumstances. Because several contributors work on the same story, they collaboratively tell the entire experience from different perspectives. These text-based approaches have been utilized e.g. in the area of business-process engineering or to exchange experiences about past projects (Perret et al. 2004; Santoro et al. 2010). Audio-based collaborative storytelling uses the renaissance of listening which is indicated by an increased demand for audio books (Philips 2007; Friederichs and Hass 2006) and podcasts (Hein and Jasuka 2007; Martens and Amann 2007) to enable the exchange of 
experiences and knowledge within a group. Thereby it provides an alternative to mainly textual techniques, e.g. wikis (Wikipedia 2011).

Within collaborative storytelling users often work on the shared story as time and opportunities arise, without explicitly coordinating it with the other participants. Similarly to reporters users collect material while working in the field and immediately integrate their changes. Often this happens while they are disconnected from the network. When connected to the network, users synchronize their changes. As a result, the shared story grows asynchronously and non-linear stories consisting of several parallel threads are created (Spaniol et al. 2006). Non-linear stories are often visualized in a so-called story graph which displays the alternative story threads. This asynchronous growth of the shared story makes it difficult to trace the story evolution. To address this issue, it is necessary to offer awareness support (Pankoke-Babatz et al. 2004; Tam and Greenberg 2006) and provide users with "an understanding of the activities of others, which provides a context for your own activity" (Dourish and Bellotti 1992).

Gutwin et al. (1996) distinguish four types of awareness: group-structural awareness, social awareness, informal awareness, and workspace awareness. In this paper, we focus on workspace awareness. Workspace awareness is "the up-to-the-moment understanding of another person's interaction with the shared workspace". Specifically, we focus on asynchronous workspace or change awareness which is defined as the ability of users to track the asynchronous changes made to a collaborative document or surface by other participants (Tam and Greenberg 2006). Asynchronous awareness explicitly focuses on two-dimensional graphical documents (Tam (2002), as cited in Tam and Greenberg (2006)) such as: figures, photos, blueprints, concept maps, graphs, UML diagrams, and collaborative workspaces containing spatially scattered artifacts. While 2D documents are widespread, techniques for displaying change awareness within them are undeveloped and are likely non-trivial (Tam (2002), as cited in Tam and Greenberg (2006)). Tam and Greenberg (2006) identified six different questions that asynchronous awareness support needs to answer:

1. Where have changes been made?

2. Who has made the changes?

3. What changes were made?

4. How were things changed?

5. When did the changes take place?

6 . Why were the changes made?

Within this paper, we use Tam and Greenberg's definition to introduce a novel approach for asynchronous awareness by visualizing the story evolution of a nonlinear story that is displayed as a directed graph. The visualization focuses on answering the questions where, who, what, how, and when. Answering these questions is most important to understand and assess recent changes in collaborative storytelling. Individual contributions within collaborative storytelling 
often reflect the personal attitude of a user. By knowing who contributed a specific part the other users can better understand the reasons for the contribution. For the same purpose, it is also important to answer what has changed. By visualizing the changes, we implicitly answer the question where changes have been made. By answering when a change has happened users are enabled to relate the change to recent events in relation to the story. Finally, answering how a story evolved helps users to relate all individual changes. We do not address the why question, as the necessary information needs to be generated explicitly by authors when committing a change (Tam and Greenberg 2006). We integrated our approach on asynchronous awareness support into our tool for audio-based collaborative storytelling and evaluated our visualization approach in an experiment with 40 users and stories of different complexity. The results show that our approach helps group members maintain asynchronous awareness and that the visualization approach can be used to create asynchronous awareness in relation to the questions who, what, when, and how.

Non-linear stories are just one example for 2D documents containing a graph as its major structure. Our design approach can therefore not just inform asynchronous awareness for non-linear storytelling but also provides the baseline for future studies focusing on asynchronous awareness support in graphs.

In the following section, we introduce our tool for collaborative audio-based storytelling. Using a scenario in which different teams collaborate on a shared story, we determine the requirements for asynchronous workspace awareness support and the corresponding visualization. We then discuss related work and present our approach in detail. We further present the setup and results of our experiment, before we conclude with a summary and outlook on future work directions.

\section{Requirements analysis}

In this section we determine the requirements for supporting asynchronous workspace awareness within CASTing, a tool for collaborative non-linear storytelling (Lukosch et al. 2011). CASTing consists of three major components: the CASTing client application, the CASTing web portal, and a centralized server. After introducing the components, we refer to a scenario in which a distributed group of students creates a joint story to compare their universities with regard to different aspects such as the quality of food or the quality of education.

\subsection{CASTing}

CASTing (Lukosch et al. 2008; Lukosch et al. 2011) supports asynchronous collaborative audio-based storytelling. It provides a client application, a web portal, and a centralized storytelling server. The storytelling server is responsible for user and project management, and provides services to access and synchronize the shared data (e.g. links between audio recordings, nodes in the story graph). 
The web portal allows users to publish podcasts and discuss, comment, vote, and reuse audio-based stories. The client application allows users to create a project team, add audio recordings, segment audio recordings, link audio recordings, and select and publish a linear story. It can be used with or without a network connection. Changes that are performed without a network connection can be synchronized with the centralized server later. Changes performed by other users can be retrieved similarly once connected to the network.

Both, the client application and the web portal support users in creating non-linear stories collaboratively. What sets non-linear stories apart from linear ones is their nature to contain several parallel threads (Spaniol et al. 2006). Non-linear stories are often visualized in a so-called story graph which displays the alternative story threads. In CASTing, a story graph consists of nodes containing audio material and linking edges.

In order to create such a non-linear story, a group has to go through a process with several stages. In the first stage, users analyze the audio material, identify segments they would like to use in the non-linear story and mark start and end point of these segments in the audio file. In the next step, users build the nonlinear story. Here, they take the identified segments and drag them onto a canvas. CASTing converts these segments into nodes of the story graph. Then users can connect these nodes through directed links, thus creating a directed graph. In the last stage, users can select a single path from the story graph. The path represents a single story and can be exported as an audio file.

The client application (see Figure 1) can be used nomadically and therefore allows users to capture experiences in situ, integrate these changes in the story

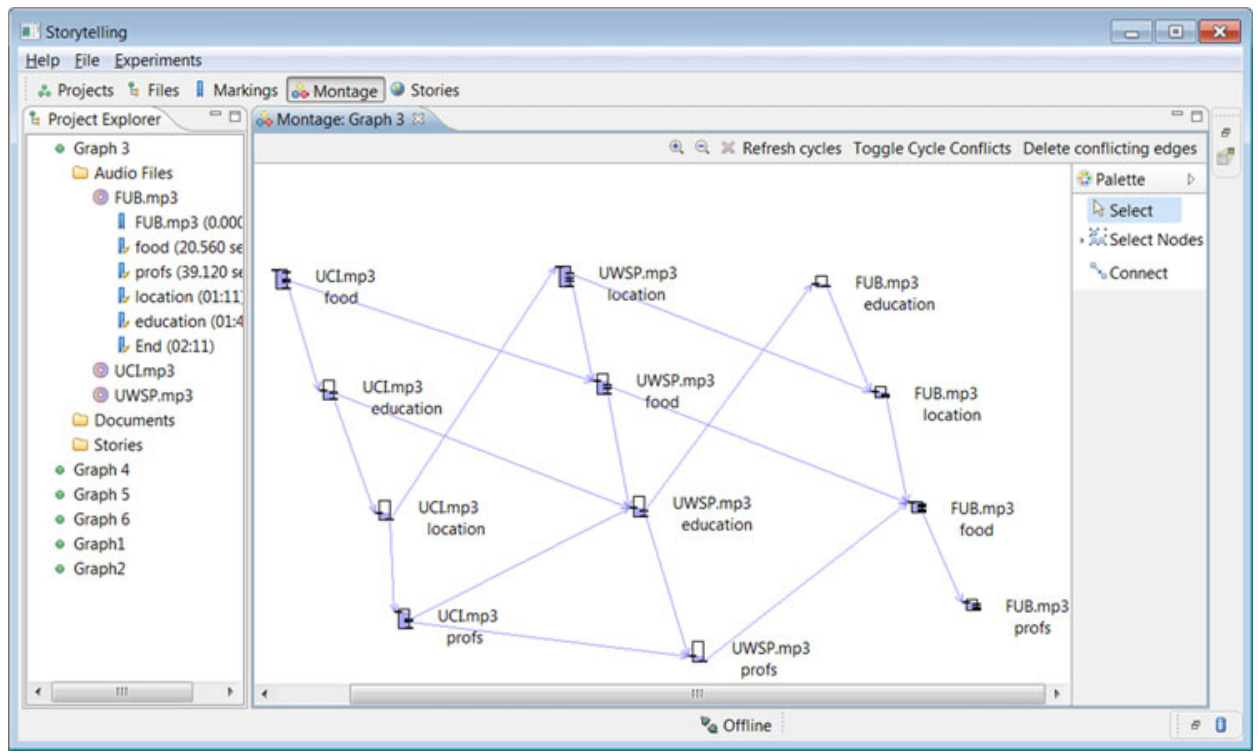

Figure 1. Story graph in the CASTing client application. 
graph and later on synchronize the changes with the server. The resulting asynchronous growth of shared data makes it difficult to trace the story graph evolution. As this can play havoc with the whole collaboration, asynchronous awareness support is essential. In the following section, we describe a typical scenario in which CASTing is used to collaboratively create a story. Based on this scenario, we derive requirement for asynchronous awareness support.

\subsection{Scenario}

A group of students from different universities in Germany and the USA made it their business to collect differences and similarities between their educational establishments. They want to jointly create stories focusing on major topics regarding their universities and use CASTing as a tool for audio-based collaborative storytelling. It is their goal to create a podcast series and discuss in every new episode another major topic regarding their universities, e.g. the quality of the food or education. Currently three students are actively working on the project: Joe is studying at the University of California in Irvine (UCI), Daniel is studying at the University of Wisconsin in Stevens Point (UWSP), and Jesse is studying at the Freie Universität Berlin in Germany (FUB).

Each of the three students has conducted an interview about studying in their university and student life in their city. In each interview they have covered the following topics: food, location, education, teachers, and jobs. Each interview was uploaded separately as a single audio file into the CASTing system. The following paragraphs describe in more detail what has happened so far within seven working days spread over several weeks.

Working day 1. Joe conducts the interviews at UCI. He uploads his audio file and creates nodes representing three sections on the quality of the food, on how nice the region is, and on the quality of the courses. He also connects these three nodes to a directed graph.

Working day 2. Daniel does the same as Joe did before for UWSP.

Working day 3. Jesse conducts the interviews at FUB. Because he is particularly interested in a comparison of the quality of the food at the different universities, Jesse connects the three sections in the interviews about food and exports it as an audio file or story with the title Food Comparison. Now the story graph has nine nodes and nine edges (see Experimental condition \#1 in Figure 8).

Working day 4. One week later Jesse decides to create some story paths to compare the teachers at the three universities. He adds one node for each 
university and links them. He also finds some connections to the existing nodes (e.g. linking nodes of one story). Overall, he ends up with twelve nodes and $\mathbf{1 8}$ edges (see Experimental condition \#2 in Figure 8).

Working day 5. A couple of days later Joe compares the job situation at the three locations. He identifies the appropriate sections, adds three nodes to the graph (one for each university) and links them to each other and to the existing nodes. The story graph has 15 nodes and 27 edges now (see Experimental condition \#3 in Figure 8).

Working day 6. Finally, Jesse wants to compare the everyday life (living) of the students at the three universities. He adds another three nodes and several edges. Altogether, the story graph has $\mathbf{1 8}$ nodes and $\mathbf{3 6}$ edges now (see Experimental condition \#4 in Figure 8).

Working day 7. The three students have worked successfully on the project for six days spread over several weeks. Now they want to broaden their comparison by adding interviews from another university. Using CASTing, they invite Albert studying at the Technische Universität Dresden in Germany to join their project. Albert decides to join and now needs an overview of the events from the last few weeks. He wants to know who is currently working on the project and how the latest story graph evolved over time. He is also interested in listening to the already existing stories and how those stories were created, because he wants to create stories in the near future as well. For that purpose, Albert is in need of adequate asynchronous awareness support that allows him to identify who has made changes, what changes were made, where changes have been made, when changes took place, and how the story graph changed over time (Tam and Greenberg 2006).

\subsection{Discussion and requirements}

The scenario above is a typical storytelling task for audio-based stories. Whenever people like the three students in our scenario work together in a shared environment (virtual or face-to-face), they need information about the activities and intentions of their co-workers. This information is important especially for successful collaboration using groupware (Dourish and Bellotti 1992).

Working with complex story graphs such as in CASTing demands advanced workspace awareness. For example, Daniel needs to know that Joe already created nodes for the UCI interview to avoid redundancies in their work. Albert needs an overview about the recent activities to see how the story graph evolved and what he could do next to support the progress of the project. Therefore he needs to know who edited the story graph, where and when these changes took place and how the changes were done. Within CASTing the story graph captures 
the current result of the collaboration and thus we base our further requirements analysis on the following hypothesis:

Hypothesis Visualizing the changes in the story graph and its evolution creates asynchronous awareness among the group members and enables them to trace the activities in relation to their story.

Based on this hypothesis and the scenario above, we now discuss the requirements for a suitable asynchronous awareness support. In our scenario Albert needs a quick overview about the activities that happened in the story graph before he joins the project. An appropriate visualization has to provide information that allows him to understand the story graph evolution based on change awareness. As mentioned in Section 1 Tam and Greenberg (Tam and Greenberg 2006) identified six different questions that asynchronous awareness support needs to answer. We focus on the questions who, what, where, when, and how. As argued before, answering these questions is most important to understand and assess recent changes in collaborative storytelling. By knowing who contributed a specific part the other users can better understand the reasons for the contribution. For the same purpose, it is also important to answer what and where something has been changed. By answering when a change has happened users are enabled to relate the change to recent events in relation to the story. Finally, answering how a story evolved helps users to relate all individual changes. We do not address the why question, as the necessary information needs to be generated explicitly by authors when committing a change (Tam and Greenberg 2006). When the who, what, where, when, and how questions are answered, Albert should be able to understand how the story graph developed over time, but also who is responsible for changes in the story graph. Thus, the following requirement has to be met:

R1: The visualization of the story graph evolution has to show information about who has made a change, what change has been made, and where, when, and how a change has been made.

Not every user might be interested in the complete evolution of the story graph. In some cases, users might only be interested in a specific time period in which they could not participate in the collaboration. Also our new group member might only be interested in the changes by a specific user, e.g. Joe, because he invited him to join the project over the CASTing web portal. These examples show that there is a need for different filter functions:

R2: The visualization has to provide different filter functions that allow users to focus on the information they are interested in (specific user or specific time period).

Within CASTing each path within the story graph represents a story. Users can select a single path in the story graph and export this path as a linear story. Thus, 
stories are important artifacts and users might be interested in how a specific story was constructed. Especially Albert needs to know this in order to create consistent stories for the podcast series. As not all users continuously participate in the story graph construction, it is hard for them to understand how the current state of the story graph has been reached. To answer how an artifact has changed over time the following requirement has to be met:

R3: The visualization has to provide a replay function that shows how the story graph has been constructed over time and furthermore has to allow users to highlight a specific story path.

\section{Related work}

In the previous section we identified the requirements for achieving awareness regarding the asynchronous growth of a story graph. In this section, we discuss existing approaches for awareness support in general and for awareness support in storytelling tools in particular, and compare these approaches to our requirements. To our knowledge there are no approaches which focus on asynchronous awareness in graphs.

Erickson and Laff (Erickson et al. 1999) added a timeline to the chat environment Babble, in order to better understand the history of a chat conversation. By design, a timeline allows one to focus on specific time periods (R2). In the timeline, each user is represented by a row. Each row displays the activities from all chats of that user, thereby focusing on that user (R2). Tool tips present additional information like the time of contribution and additional information about the user. The timeline enables users to discover when other users are interacting in the collaboration space and it allows users to adjust their working hours so that synchronous collaboration is possible when needed. Thus, the timeline is a suitable awareness mechanism indicating when a user was present. However, a timeline does not allow users to explore how an artifact such as a chat has developed over time (R3).

Virtual School is a collaboration space for student interaction. A user study has revealed that collaboration broke down several times due to lack of activity awareness (Carroll et al. 2003). One solution was to integrate a timeline into the student's workspace (Ganoe et al. 2004). For each project, the timeline showed different documents. Changes to the documents were represented by the icons on the time axis. To access documents, users were forced to select them in the timeline instead of from a list of documents, making the timeline an integral part of daily work.

User studies (Ganoe et al. 2003) have shown that the timeline was of great value to people who were observing the group's progress. For example when there were white areas on the timeline, teachers queried the students responsible for those documents about problems in their group process and provided help. Here, the 
timeline allows teachers to focus on the student's workspace. However, the timeline does not allow them to focus on a single student across several projects (R2).

Overall, a timeline allows users to focus on two dimensions, the time period and one other dimension like actors or activities. It is noteworthy that in both cases the timeline does not create awareness for 2D documents such as a graph.

DreamObjects (Lukosch 2004) is a platform for managing shared data of synchronous groupware transparently. It offers flexible and extensible solutions for data distribution, concurrency control, data persistency, latecomer support, and user interface notification. Within DreamObjects, latecomers can choose between a direct state transfer and a replay of how the current state has been reached (Lukosch 2003). The replay mechanism addresses aspects of asynchronous awareness (Lauwers and Lantz 1990) both for sequential and 2D documents such as story graphs. Tam and Greenberg (2006) note that the replay mechanism is a good solution to answer the question how things were changed, because a replay allows a user to retrace the evolution of an artifact step by step. However, the replay mechanism does not cover the entire range of asynchronous awareness. For example, in DreamObjects it is not possible to focus on actors (R2) or artifacts (R3). Overall, it offers a possibility to target the evolution of the story graph through animation.

Facebook offers an activity feed (Facebook Developers 2010), to keep users appraised of the activities of their friends, thereby providing some meta-information. This awareness mechanism allows users to follow actions, but does not offer help in focusing on a particular friend (R2) or activities in a time period (R2).

Apart from the discussed applications there exist quite a few tools that support users in collaboratively creating stories. However, these tools do not provide adequate support for asynchronous awareness.

TellStory (Perret et al. 2004) is a collaborative application that supports groups in creating linear text-based stories. However, TellStory does not provide any awareness support regarding the growth of the story.

PhotoStory (Schäfer et al. 2004) uses storytelling to increase the awareness in the group about its external presentation but also its social activities. For that purpose, the group can create stories that consist of a series of pictures with corresponding subtitles. PhotoStory uses $B S C W$ (Bentley et al. 1997) as a collaborative workspace. BSCW-specific data structures provide the basis for annotations of the pictures. Apart from story related attributes such as type of event or position of a picture in the drama arc, awareness related attributes like author and creation date are provided. While PhotoStory provides some meta-information about the images, it does not support the users in understanding the evolution of the story by focusing on specific time periods or users (R2).

The internet-based storytelling application Voicethread (VoiceThread LLC 2011) supports groups in creating sequences of images or video clips. Users can add textual, audio- or video-based comments to these multimedia artifacts and hence create a digital story. These comments can be associated with an author 
through a picture. The comments can be played back in the order of their creation. However, Voicethread does not employ filtering mechanisms for supporting users in understanding the evolution of the story (R2).

TellStory, PhotoStory, and Voicethread all focus on linear stories. There are also storytelling applications that support users in creating non-linear stories. For example, (Röber et al. 2006) introduce the concept of Interactive Audiobooks where audiobased stories are combined with interactive elements to form a non-linear story. This story is represented as a story-graph to the editors of the story. Another example is MIST (Spaniol et al. 2006). MIST allows users to create non-linear stories using multimedia elements such as text, images, audio and video recordings. However, both Interactive Audiobooks and MIST do not focus on collaboration. In contrast, StoryMapper (Acosta et al. 2004) supports groups in telling a nonlinear story modeled as a conceptual map. Each node in such a map represents an event consisting of facts, the time of the event, and the involved actors and links to related multimedia artifacts. The edges represent semantic relationships between the nodes. The border color of a node is used to indicate who created that node. StoryMapper provides some meta-information and utilizes color coding to show which user created a node, thereby partially addressing (R2). However, it does not have any mechanism that helps users to focus on time periods (R2) or parts of the story graph (R3). Similar to CASTing, these three applications utilize graphs to visualize the non-linear story.

The discussion above shows that existing system are aware of the need to provide awareness information. None of the systems, however, offers different filters or allows users to replay the recent changes while highlighting important artifacts. Furthermore, most systems deal with sequential documents instead of $2 \mathrm{D}$ documents such as a story graph. Thus, we present our approach to address our identified requirements in the next section.

\section{Approach}

In Section 2 we identified several requirements to improve asynchronous workspace awareness for collaborative storytelling by visualizing the story graph evolution. The main hub for exchanging ideas and discuss the evolution of a story is the CASTing web portal. For that purpose, we developed and integrated a prototype in the CASTing web portal to test our hypothesis that visualizing the story graph evolution creates asynchronous awareness among the group members and enables them to trace the activities in relation to their story.

Our prototype is divided into two main parts (see Figure 2). The upper part displays the actual story graph visualization (R1). The lower part displays the control functions to filter the displayed information in the story graph (R2) or start the replay of the story graph (R3) to understand how the story graph evolved. In the following, we describe in more detail how we addressed the requirements $\mathrm{R} 1, \mathrm{R} 2$, and $\mathrm{R} 3$. 

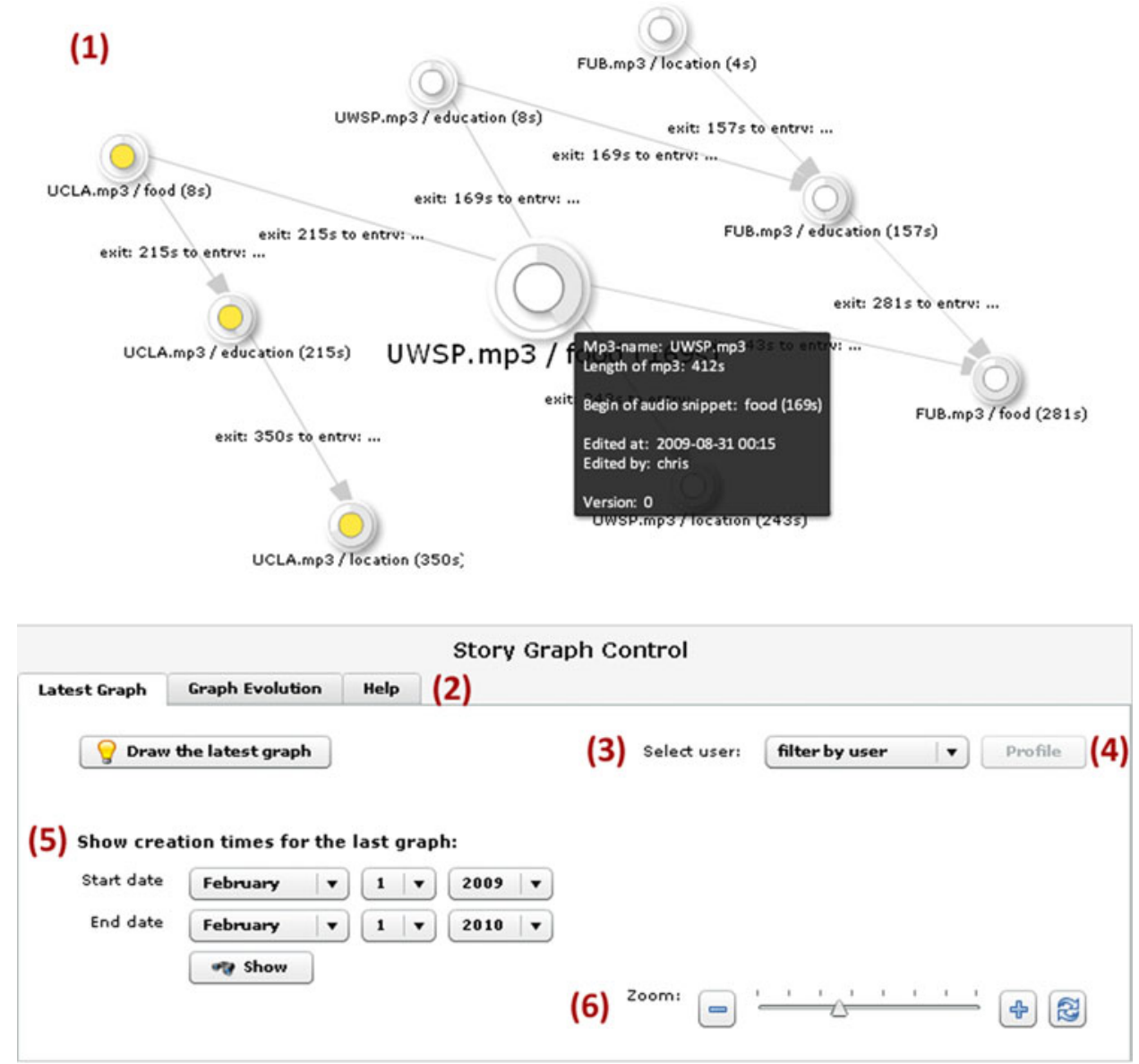

Figure 2. Story graph visualization.

\subsection{Story graph visualization (R1)}

The visualization (see Figure 2 (1)) shows a story graph. We chose this visualization form as the story graph is also used in the CASTing client application. Users are familiar with the client visualization as they need to use the client while creating a story collaboratively and asynchronously. When considering the story graph visualization in the client application, we have to design a simple and directed graph without loops and the possibility to display single nodes. In this way, users can still recognize the story graph they worked with in the CASTing client application.

In order to overcome the different lengths of the audio recordings in the CASTing client application, we decided to display all audio recordings independent from their length as circles of the same size. The grey colored 
background changes depending on the real length of the audio recording and the part of the audio recording being used in the story. Resulting from this visualization we save visualization space, which is very important due to the limited space in the CASTing web portal.

To display the story graph evolution as effective as possible, there is a limited set of visual properties that are detected very rapidly and accurately by the human low-level visual system, e.g. the color of an object. Following these preattentive properties (Healey 2010), we colored the inner circle of the nodes in the CASTing web portal (see Figure 3 (1)). The more intense a color, the more recent a node. This enables users to preattentively recognize the age of a node and answer the question "When did the changes take place?" (Tam and Greenberg 2006):

- A white inner circle represents nodes which were created in the last year.

- A yellow inner circle represents nodes which were created in the last month.

- An orange inner circle represents nodes which were created on the current day.

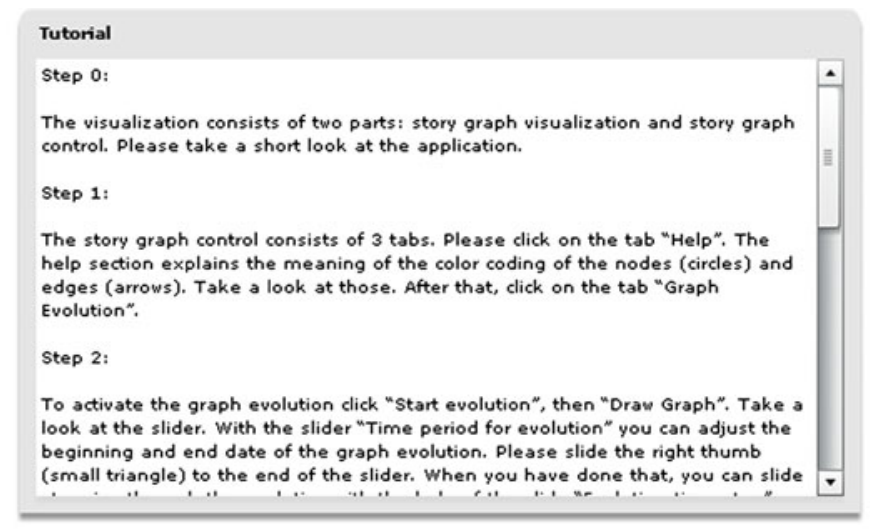

\begin{tabular}{l|l|l|l|}
\hline & & Story Graph Control \\
\hline Latest Graph & Graph Evolution & Help & \\
\hline
\end{tabular}

(1) Age of Audio Nodes

\section{(2)}

Audio Nodes

(3) Edges

(4)

(1) Tutorial
Nodes from this day

Nodes from last month

Nodes from last year

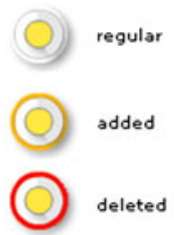

regular

added

deleted

Figure 3. Help section in the story graph control. 
The outer ring of a node (see Figure 3 (2)) is used to indicate the state of the node and answer the question "What changes were made?" (Tam and Greenberg 2006). If the outer ring of the node is highlighted in orange, the node was created at the chosen point in time. If it is red, a user has deleted the node at the chosen point in time.

An arrow represents an edge in the story graph of the CASTing client application and connects different parts of audio recordings. For the edges, we use the same color coding as we use for the inner circles of the nodes (see Figure 3 (3)). Additionally, we included tool tips which provide information about the nodes and edges in the visualization (R1), e.g. name of audio file, length of audio file, begin of audio snippet, time of last editing, person who edited the node the last time, and a version number.

The help section in the story graph control (see Figure 3) provides a graphical and textual description of the colors and displays of a node or an edge. The help section is meant to be a legend of the story graph evolution, but it also offers a tutorial (see Figure 3 (4)) for new users.

\subsection{Information filter functions (R2)}

When visualizing the story graph evolution, users can filter certain information. The story graph control (see Figure 2 (2)) is divided into three parts:

\section{Latest Graph \\ 2. Graph Evolution \\ 3. Help}

The Latest Graph control allows users to explore who did what and where in the latest story graph. The story graph can be filtered by user (see Figure 2 (3)) which highlights the edges and the outer rings of the nodes created by the selected user (R2). A more detailed view on this filter and a sample result is shown in Figure 4. Thereby, this filter can be used to identify who created what artifact in the most current view and thus answers the question "Who has made the changes?" (Tam and Greenberg 2006). It also allows users to literally see where in the latest graph a person has changed something. In addition, users can choose to display the profile of the selected user (see Figure 2 (4)).

The story graph can also be filtered by creation date of nodes and edges (R2) in the project (see Figure 2(5)). A more detailed view on this filter and a sample result is shown in Figure 5. If a node or an edge was created in the selected time period, these nodes and edges are highlighted (R2). This function offers the ability to see when an artifact was created in the latest graph view. By using this function the question "When did the changes take place?" (Tam and Greenberg 2006) is answered for the users. 
(a) User filter control

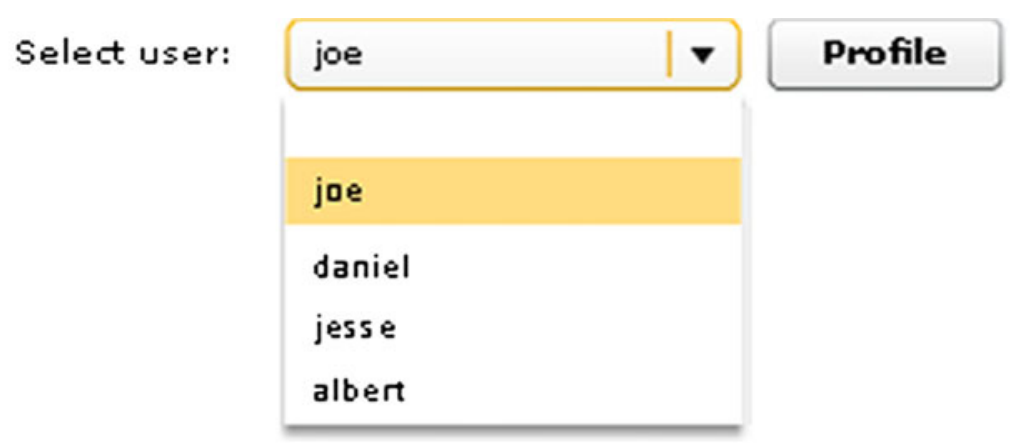

(b) Result of filtering by user

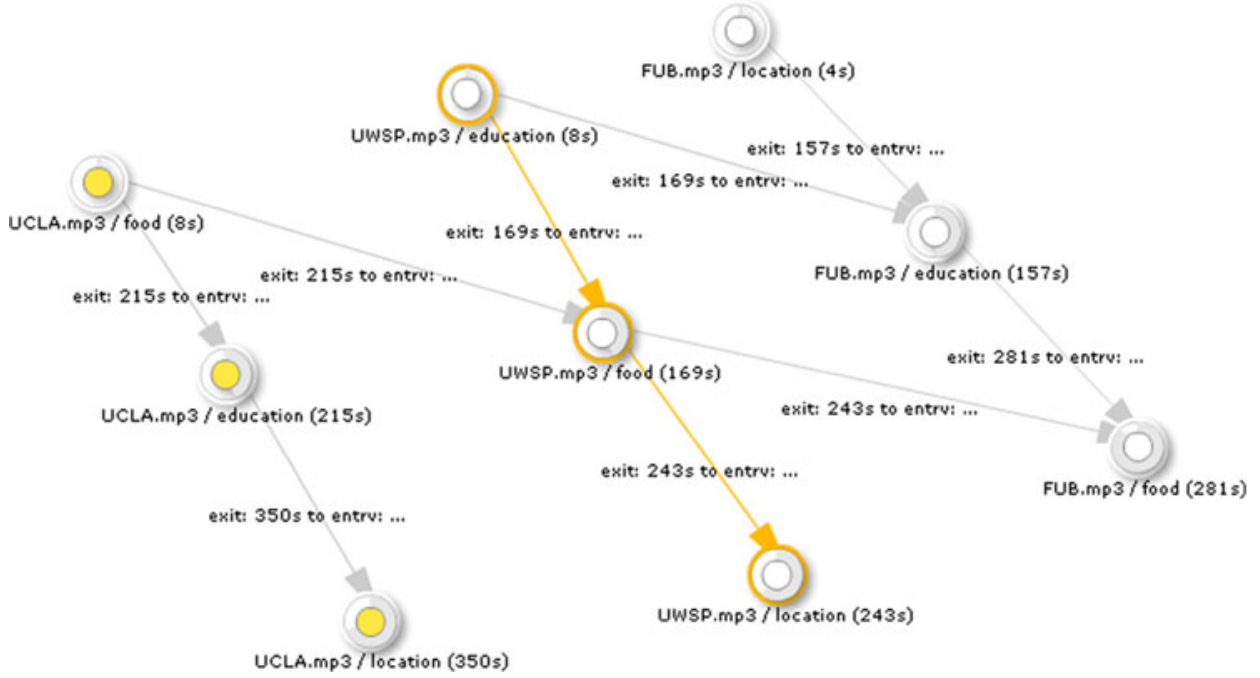

Figure 4. Filtering by user.

Overall, the latest graph control can be used to answer who has changed an artifact, what has been changed, and when it has been changed.

The Latest Graph control also offers a zoom feature (see Figure 2 (6)) for zooming in and out of the latest story graph. Thereby, we allow users to take a look at the full graph or have a closer look at specific nodes or edges. The zoom function is also available for the Graph Evolution as described in the following.

\subsection{Evolution of the story graph (R3)}

The second part of the story graph control is the Graph Evolution (see Figure 6). The Graph Evolution control addresses the question on how an artifact has 
(a) Creation time filter control

Show creation times for the last graph:

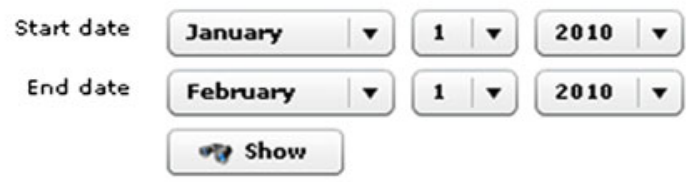

(b) Result of filtering by creation times

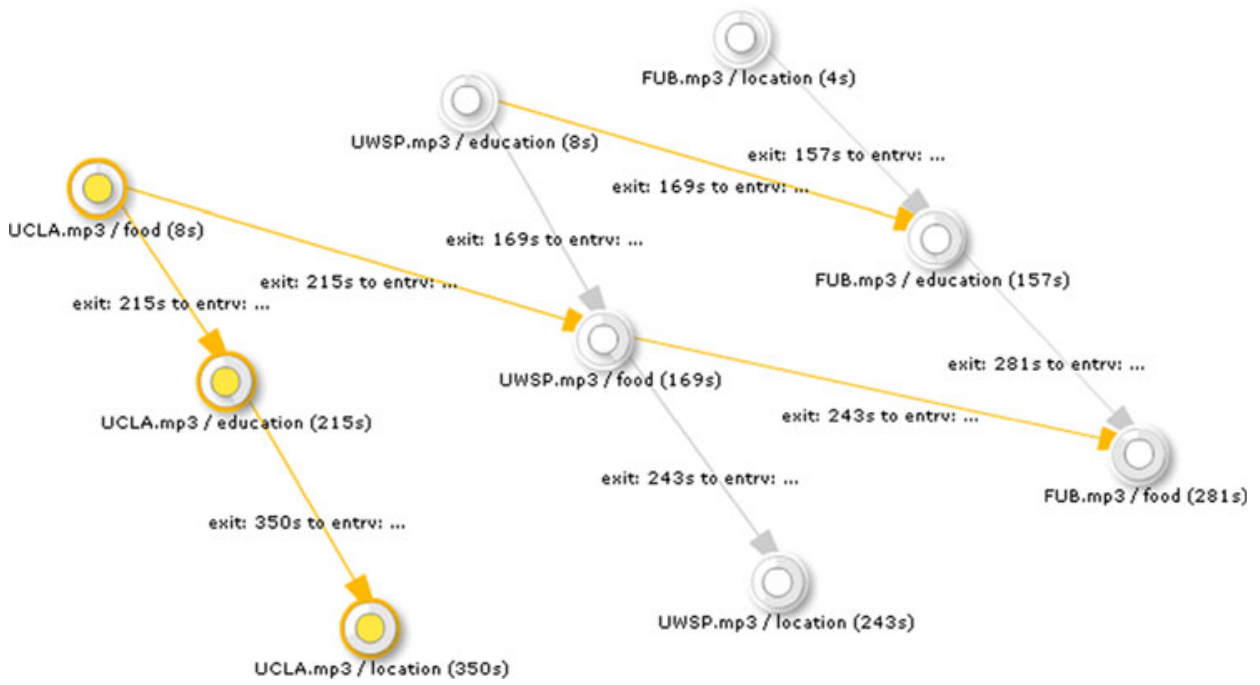

Figure 5. Filtering by creation times.

changed over time by providing several filter functions that allow users to display the activities that took place on the story graph according to a TIMELINE (Schümmer and Lukosch 2007). These filters allow users to retrieve information about all graph artifacts and on how they were created, modified or deleted over time.

By selecting a story (see Figure 6 (1)), the user filters the story graph evolution with regard to the created stories in the project. If a node or an edge is part of the selected story, then these nodes and edges are highlighted in the story graph. This filter offers the ability to see how the stories in the project were created. Additionally, a user can go directly to the rating of the selected story in the CASTing web portal.

The evolution function allows a user to REPLAY (Schümmer and Lukosch 2007) how the story graph developed over time (R3) and how the current state of the collaboration has been reached. Two sliders allow a user to replay the story evolution. The lower slider (see Figure 6 (3)) allows a user to pre-select a specific time period and the upper slider (see Figure 6 (2)) enables the user to slide through that selected time period. The current slide 

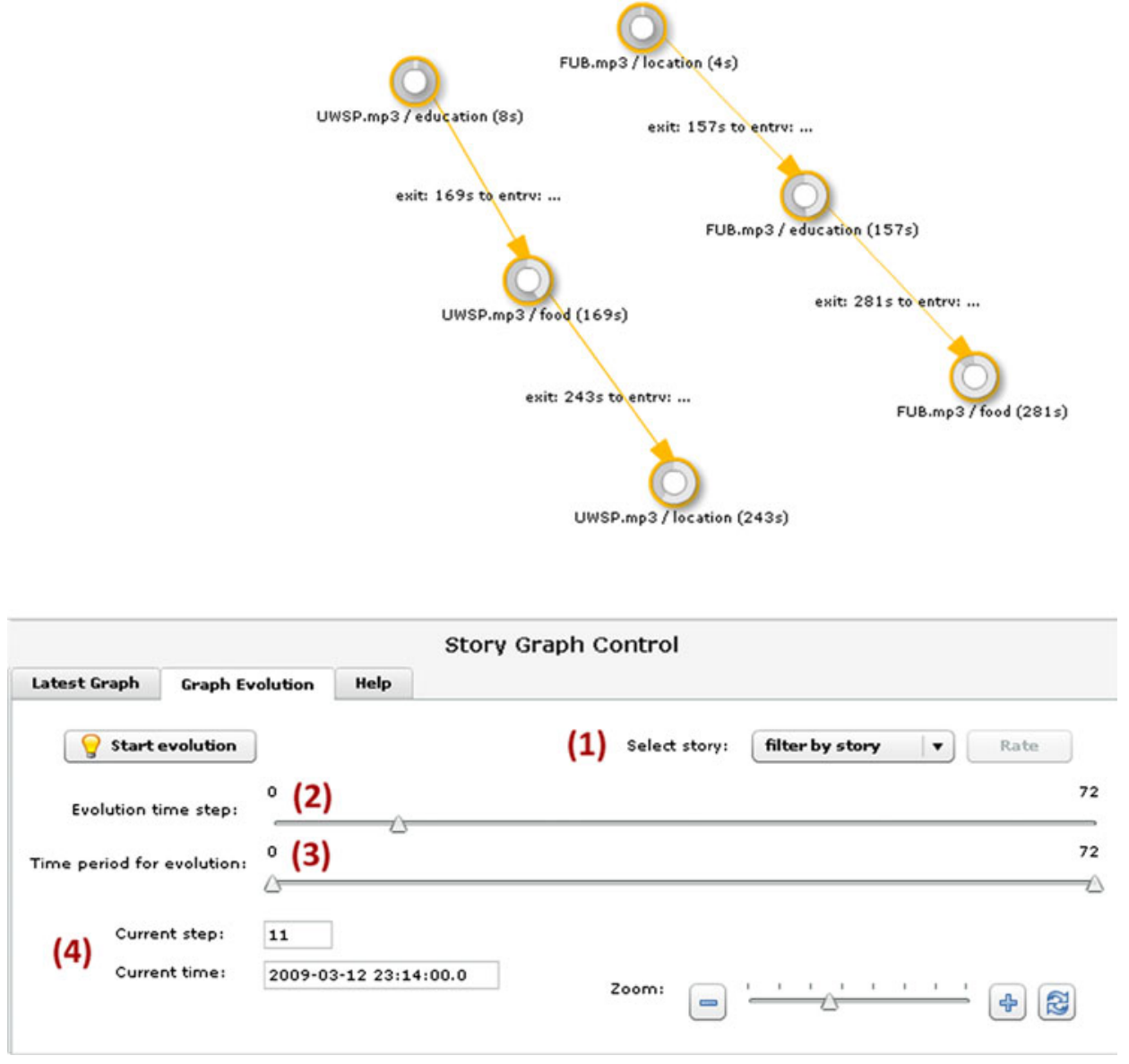

Figure 6. Story graph evolution.

step and time are displayed in the lower part of the evolution function (see Figure 6 (4)).

\subsection{Summary}

The functionalities above address the identified requirements R1, R2 and R3. Considering asynchronous workspace awareness the following questions (Tam and Greenberg 2006) are answered:

1. Where have changes been made?: By visualizing the story graph evolution and highlighting the changes using different color schemes, users become aware of the location of changes. 
2. Who has made the changes?: By offering users to filter by user and including tool tips, users become aware of the originator of changes. Additionally they can assess further information about a user via user profiles.

3. What changes were made?: The different color codes highlight what recent changes were made and make users aware of these changes.

4. How were things changed?: By replaying the story evolution users can understand how a story has been created.

5. When did the changes take place?: By offering users to filter by creation date of nodes and edges, users become aware of when changes were conducted. Similarly the color coding of the inner rings supports users in assessing when changes happened. Furthermore users can track the development of nodes and edges over time via the story graph evolution function.

\section{Implementation}

CASTing itself consists of three major components (see Figure 7): the CASTing client, the CASTing web portal, and a centralized storytelling server. The client application allows users to asynchronously create a project team, add audio recordings, segment audio recordings, link audio recordings and select and publish a linear story. Using the client application users can retrieve the most current version of the story graph and synchronize their local changes. The CASTing web portal allows users to publish podcasts on the Web and discuss, comment, vote and reuse audio-based stories. Both the web portal and the client access a centralized storytelling server. The server is responsible for user and project management, and provides services to access and synchronize the shared data (e.g. links between audio recordings, nodes in the story graph). These services are contained in the Storytelling Kernel and can be accessed both from the client application and the web portal.

In order to support the different filtering and highlighting functions as well as the story graph evolution, we created a persistent history of the user's activities. Using this history we can filter information and reconstruct the state of the story graph for a specific point in time. For creating and accessing the history two components were added to the storytelling kernel: an Activity Log (Schümmer and Lukosch 2007) and a service which utilizes the activity log. More precisely, the activity log records every change to the story graph in the database. The client as well as the web portal interact with the log by adding, consuming, or querying activities. Additionally, a service utilizing the activity log to provide information for the visualization and the filter mechanisms was implemented. The activity log stores

- the type of the activity, such as editing, creating, removing elements from the story graph, 


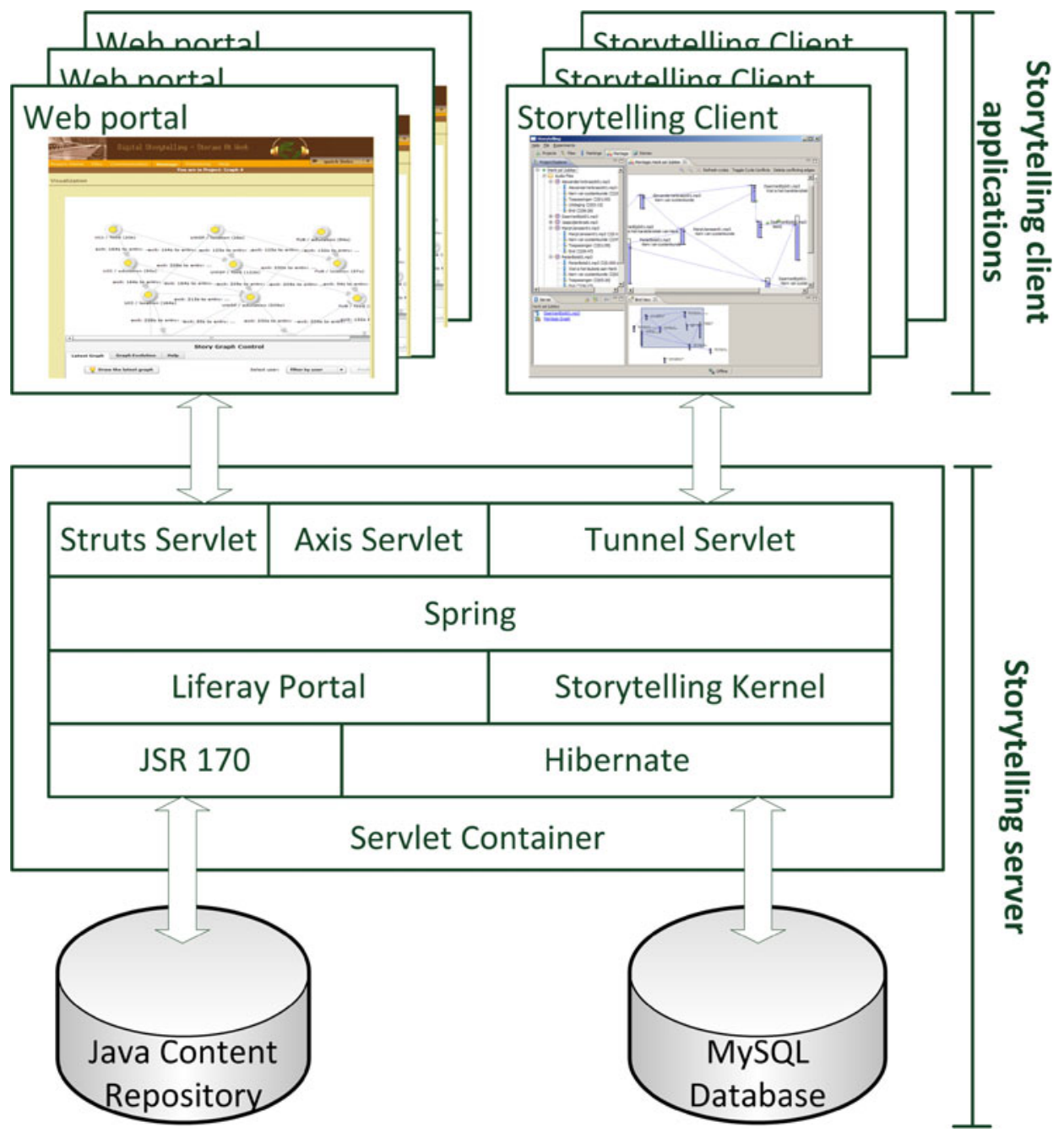

Figure 7. CASTing system architecture.

- the element of the story graph that was touched during the activity,

- the time at which the activity took place and

- the user who performed the activity.

The graph visualization itself and the control sections were developed as rich internet applications (RIA) and integrated into the web portal. They are based on BirdEye (Birdeye Group 2011) and Adobe Flex (Adobe Systems Incorporated 2011). BirdEye is a community project to advance the design and development of a comprehensive open source information visualization and visual analytics library for Adobe Flex. The library enables the creation of multi-dimensional data visualization interfaces for the analysis and presentation of information. 


\section{Evaluation}

In this section, we evaluate the visualization based on the framework for asynchronous awareness (Tam and Greenberg 2006) by testing the following hypothesis:

Hypothesis Visualizing the changes in the story graph and its evolution creates asynchronous awareness among the group members and enables them to trace the activities in relation to their story.

The asynchronous awareness framework provides detailed questions for its different categories. However, not all of these categories are evaluated. First, the asynchronous awareness framework discusses three different views: the artifactbased view, the person-based view, and the workspace view. The workspace view goes beyond the story graph and includes audio files and time indexes in these files. It is therefore outside the scope of our approach, and consequentially not evaluated. Second, as argued in the introduction, we do not address the question why. Third, the evaluation does not address the question Who made changes with this person? and Who has this person interacted with?. Both questions refer to synchronous interactions among the users of the system. As CASTing is only supporting asynchronous interactions the question of synchronous co-authorship is irrelevant for the users of the system. Last, the question how is supported by the replay mechanism of the visualization. This replay function addresses the question how changes were made and how a person has changed things. It is a common technique for addressing asynchronous awareness related to the question how changes were made (see also Section 3). It is therefore not necessary to further evaluate whether the visualization supports this aspect of the awareness framework.

Overall, the focus of the evaluation regarding asynchronous awareness is on the questions who, when, and what for the artifact- and person-based view. Table 1 gives an overview about those questions of the framework that we address in our evaluation.

In addition to the questions derived from the asynchronous awareness framework, we also evaluate whether the user interface is easy to handle for the project members. If it is easy then the users are able to get all the information they need. So the asynchronous workspace awareness is supported in an indirect way.

\subsection{Experimental design and procedure}

In order to test our hypothesis we conducted an experiment with four conditions, each consisting of a different story graph (see Figure 8). The story graphs increase in complexity and correspond to the scenario in Section 2.2. 


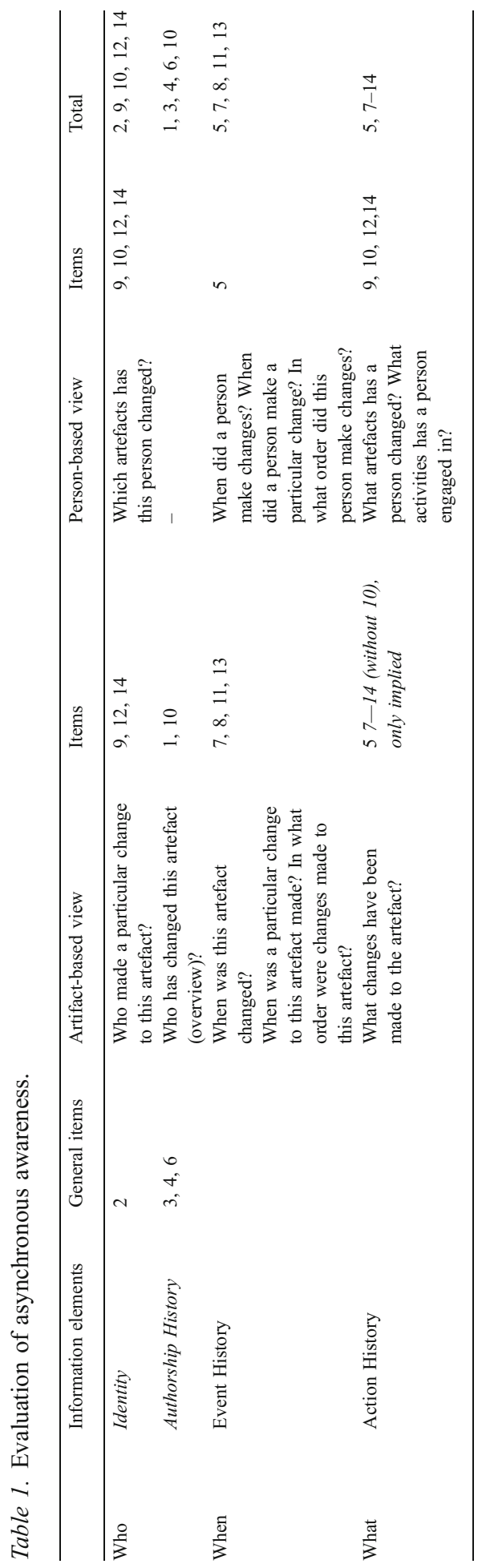


The experimental conditions differ not just with regard to the complexity of the graph, but also with regard to the scrolling behavior required of the participants. The first condition consisted of a graph with nine nodes and nine edges (see Figure 8 (a)). The participants were able to see the entire graph without scrolling. The second condition consisted of a graph with twelve nodes and 18 edges (see Figure 8 (b)). We thus added three nodes and seven edges to the existing graph. Here, the participants did not have to scroll, but had to deal with a more complex graph. For the third condition we added three nodes and nine edges to the existing graph (see Figure 8 (b)). In this condition the participants had to scroll a little bit to see the entire graph. For the last condition we used a graph with 18 nodes and 36 edges (see Figure 8 (d)). This graph was the most complex one and the participants had to scroll in all directions to see the entire graph. Figure 9 provides an overview about the different graph complexities.

Overall, the experimental design allows us to study how the size and complexity of the story graph influences the asynchronous awareness of the participants, but it does not provide us with a control condition. Literature also does not provide a basis for comparison for asynchronous awareness support in graphs (see also Section 3). However, by comparing the results obtained in the experimental conditions with chance levels for asynchronous awareness, we can assess whether the visualization has an effect on the awareness level of the participants (see also Section 6.3 for details).

The experiment itself was divided into two phases. In the first phase each participant was provided with basic information about storytelling and what he/ she can expect to see in the visualization prototype. Thus, the participant acquired basic knowledge about the scenario for completing the experiment. In addition, each participant provided demographic information as well as information about their previous knowledge (see Figure 10 for the results). In the second phase each participant worked with the visualization and filled out a digital questionnaire at the same time. The participant was free to choose the time at which he or she completed the experiment.

\subsection{Participants}

Altogether 40 voluntary participants within the age of 22 to 53 took part in the experiment. The participants were assigned to the four experimental conditions, with ten participants per condition. Eleven of them were female and 29 were male. The participants had different cultural backgrounds (Europe, Africa, North America and Asia). Overall, it took the participants of the first three conditions 21 minutes on average to complete the session. In the fourth condition, the most complex graph, they needed 31 minutes on average. 
(a) Experimental condition 1

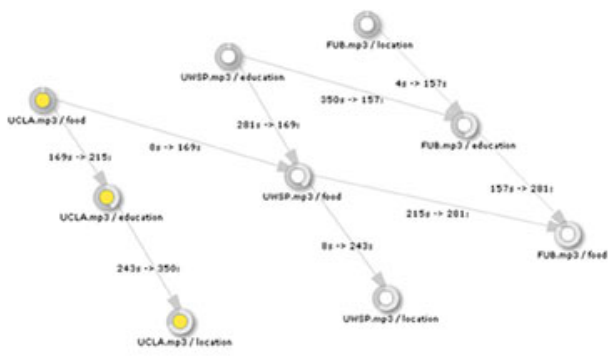

(b) Experimental condition 2

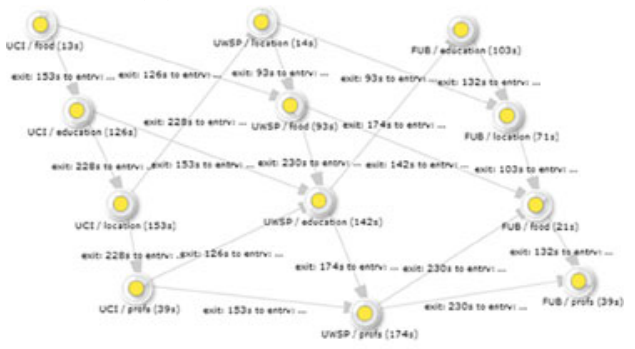

(c) Experimental condition 3

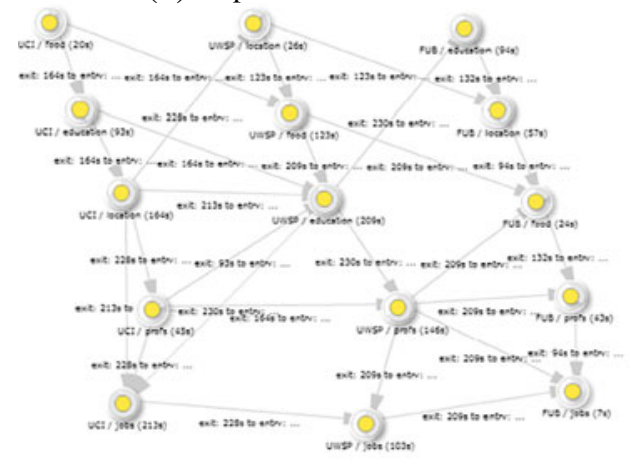

(d) Experimental condition 4

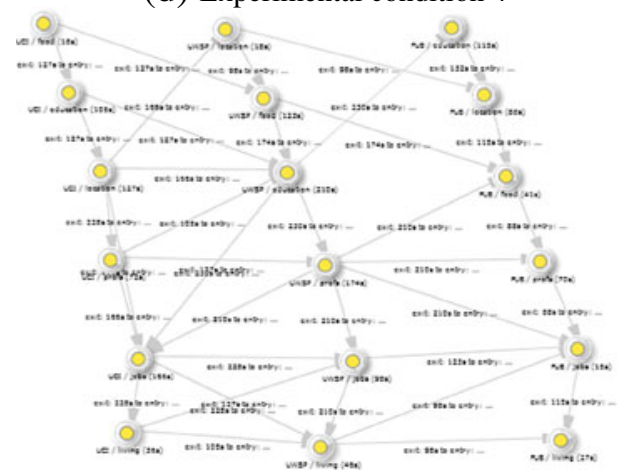

Figure 8. Story graphs used in the four experimental conditions. 


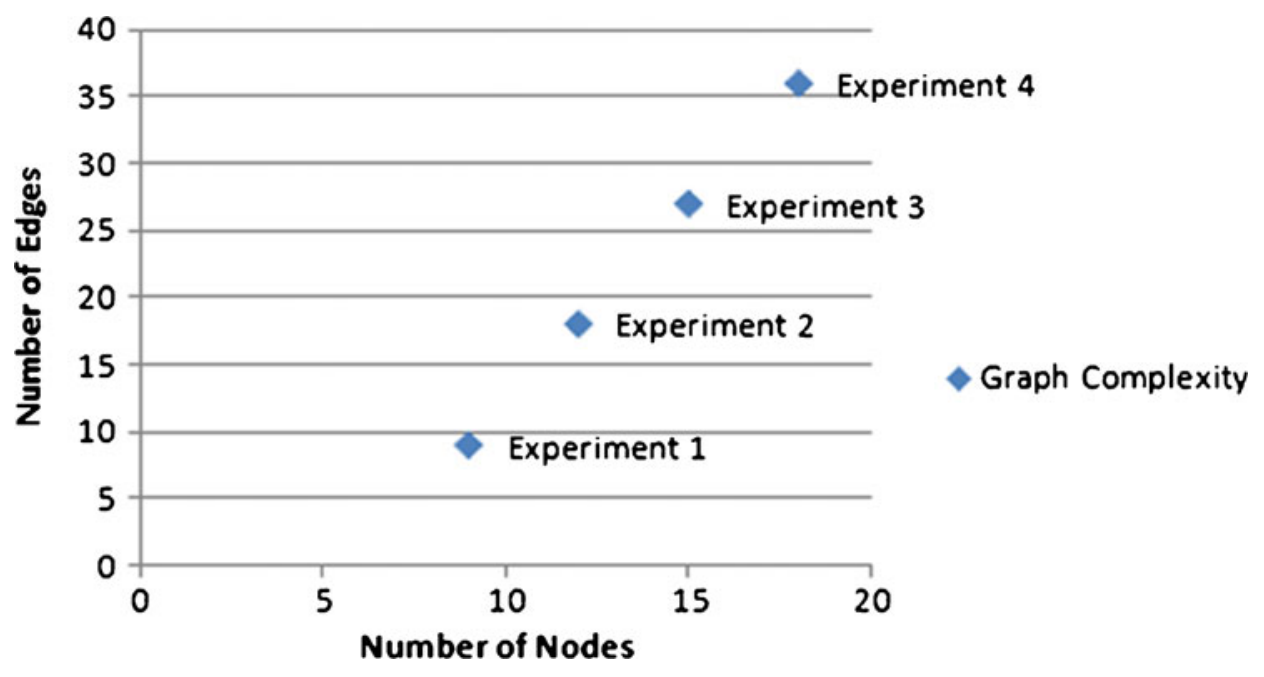

Figure 9. Graph complexity.

Before the experiment, we asked the participants to judge their experience with storytelling, groupware, and group awareness support (see Figure 10). Altogether, the participants had little experience with storytelling and group awareness support. Only three participants had used storytelling techniques, and another three considered themselves experts in this area. Similarly, only nine participants had used group awareness techniques, and only one participant considered him- or herself an expert. Both for storytelling and group awareness support, at least $75 \%$ of the participants claimed to have not used these techniques before. In contrast, the experience with groupware is much higher. $50 \%$ of the participants have at least used groupware before. Eight of these consider themselves experts in this area. All in all, the experience level of the participants was mixed from "not heard of it before" to "expert" for all three theoretical categories.

\subsection{Measurements and analysis}

In order to evaluate how bad or well the visualization supports asynchronous awareness, we provided the participants with a questionnaire with multiplechoice questions addressing different categories in the awareness framework. Table 2 provides an overview over the items, and Table 1 relates these items to the different categories of the awareness framework. The items do not address the question where changes were made. By interacting with changed nodes and edges in the visualization users already demonstrate awareness that changes have been 
(a) Experience of participants with storytelling

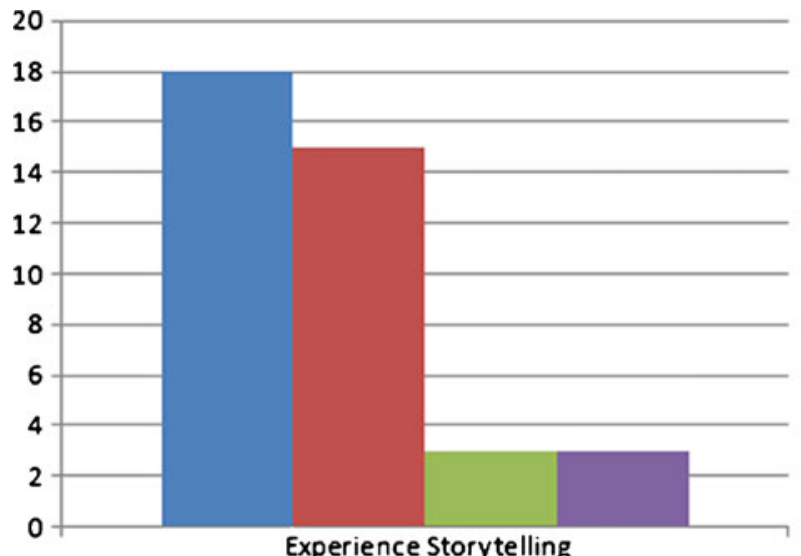

Not heard of it

a Heard of it

Ensed it already

Expert

(b) Experience of participants with groupware
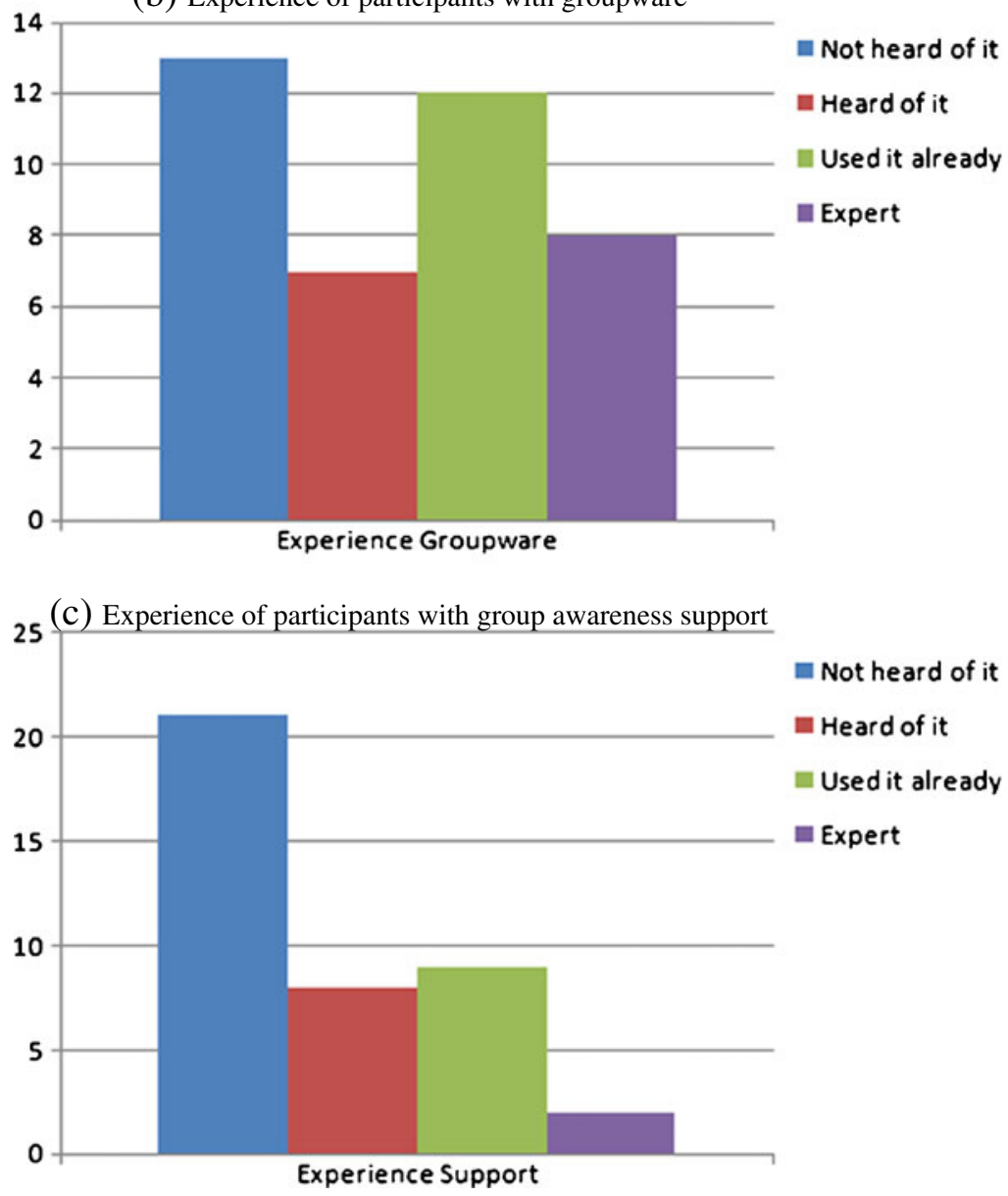

Figure 10. Experiences of participants. 
made to that artifact. Thus, where changes have been made is not explicitly measured.

In order to address the increasing complexity of the story graphs and to ensure that participants had to look at the entire story graph the number of questions increases with the complexity of the story graph.

We extended the authorship history of the awareness framework with three questions relating to the activity levels of the characters working on the story graph. Specifically, we assessed whether the participants showed any awareness on who is the most active or inactive person working on the story graph (item 3 and 4 respectively). This kind of information is particularly relevant for any newcomer to an existing project, because it indicates the people who have the best (or worst) understanding of the story graph. Even though these items are relevant for the authorship history, they do not have a clear mapping to any view in the awareness framework, because they ask for a summary instead of particular details about what an author did. Thus, we treated them as general items in this category. In addition to the activity levels, we assessed whether the participants showed any awareness of who was the last person working on the story graph (item 6). This information is relevant for anybody who wants to continue to work on the story graph. As with the activity levels, this information could not be assigned to any specific view. Even though the question clearly asks about an author of the story graph, it also contains a time component making it difficult to match a view to this question.

For each participant we calculated the percentage (the score) of correct answers for the different categories in the awareness framework. Furthermore, we

Table 2. Multiple-choice questions for assessing awareness.

\begin{tabular}{|c|c|c|c|c|c|}
\hline \multirow[t]{2}{*}{ Item } & \multirow[t]{2}{*}{ Question } & \multicolumn{4}{|c|}{ Used in Condition } \\
\hline & & 1 & 2 & 3 & 4 \\
\hline 1 & Which persons have applied changes to the story graph? & $\mathrm{x}$ & $\mathrm{x}$ & $\mathrm{x}$ & $\mathrm{x}$ \\
\hline 2 & What is John's last name & $\mathrm{x}$ & $\mathrm{x}$ & $\mathrm{x}$ & $\mathrm{x}$ \\
\hline 3 & Which person is the most active regarding to the story graph & $\mathrm{x}$ & $\mathrm{x}$ & $\mathrm{x}$ & $\mathrm{x}$ \\
\hline 4 & Which person is the most inactive regarding to the story graph & $\mathrm{x}$ & $\mathrm{x}$ & $\mathrm{x}$ & $\mathrm{x}$ \\
\hline 5 & What did Jesse do on March $20^{\text {th }}$ & $\mathrm{x}$ & $\mathrm{x}$ & $\mathrm{x}$ & $\mathrm{x}$ \\
\hline 6 & Which person was the last working on the story graph? & $\mathrm{x}$ & $\mathrm{x}$ & $\mathrm{x}$ & $\mathrm{x}$ \\
\hline 7 & At which point in time was added the node "UWSP / location"? & $\mathrm{x}$ & $\mathrm{x}$ & $\mathrm{x}$ & $\mathrm{x}$ \\
\hline 8 & At which point in time was added "UCI / profs"? & - & $\mathrm{x}$ & $\mathrm{x}$ & $\mathrm{x}$ \\
\hline 9 & Who added the edge "UWSP / profs" to "FUB / profs"? & $\mathrm{x}$ & $\mathrm{x}$ & $\mathrm{x}$ & $\mathrm{x}$ \\
\hline 10 & Which person would you contact, if you have questions to the UWSP Interview? & $\mathrm{x}$ & $\mathrm{x}$ & $\mathrm{x}$ & $\mathrm{x}$ \\
\hline 11 & At which point in time was added the node "FUB /jobs"? & - & - & $\mathrm{x}$ & $\mathrm{x}$ \\
\hline 12 & Who added the edge from "UCI / jobs" to "UWSP / jobs"? & - & - & $\mathrm{x}$ & $\mathrm{x}$ \\
\hline 13 & At which point in time was added the node "UWSP / living"? & - & - & - & $\mathrm{x}$ \\
\hline 14 & Who added the edge from "UCI / living" to "UWSP / living"? & - & - & - & $\mathrm{x}$ \\
\hline
\end{tabular}


calculated the mean score for each experimental condition and each assessed category of the awareness framework.

The experiment does not contain a control group. In order to provide a baseline and thus assess whether the awareness mechanisms are effective, we obtained a chance level by simulating how somebody trying to guess the right answer would have performed. First, the items in the questionnaire were answered using a random number generator. Altogether, 100 additional cases forming a 'random group' were created. This 'random group' was then analyzed using the same methods as for the experimental conditions. Specifically, a mean random result ${ }^{1}$ was obtained for the different categories of the awareness framework and for each task.

A Mann-Whitney U test (see e.g. Field 2009) was used to assess whether there are significant differences between awareness levels in the experimental conditions and the chance level, or between awareness levels in different experimental conditions.

Regarding usability aspects of the visualization we obtained qualitative as well as quantitative feedback from the participants. The quantitative measurements were obtained using the following two items (using a five-point Likert scale):

- The handling of the story graph visualization was easy to learn.

- I always knew where I am and what to do.

\section{Evaluation results}

In the following, we analyze and discuss the results of the experiment and compare the experimental conditions with each other and with the chance level. Table 3 provides an overview about the mean scores per category of the awareness framework. The mean scores per item in the questionnaire can be found in the Appendix 9 in Table 4. The Appendix also contains the results of the Mann-Whitney $\mathrm{U}$ tests in Tables 5 and 6.

The mean values for all experimental conditions are considerably higher than the chance levels (see Table 3) for all tested awareness categories. In addition, the Mann-Whitney $U$ tests (see Table 6) showed that these differences are significant. There is one exception, however. For the most complex graph (experimental condition four) the awareness displayed by the participants in relation to the question when in the person-based view is not better than the chance level. Consequently, the visualization is effective in

\footnotetext{
${ }^{1}$ Using probability theory we could have obtained exact probabilities for guessing the right answer. However, without simulated cases we could not assess whether the differences are significant.
} 
Table 3. Mean score per category in the awareness framework.

\begin{tabular}{|c|c|c|c|c|c|c|c|}
\hline Awareness & Category & & $\begin{array}{l}\text { Condition } \\
1\end{array}$ & $\begin{array}{l}\text { Condition } \\
2\end{array}$ & $\begin{array}{l}\text { Conditon } \\
3\end{array}$ & $\begin{array}{l}\text { Condition } \\
4\end{array}$ & $\begin{array}{l}\text { Random } \\
\text { results }\end{array}$ \\
\hline \multirow[t]{8}{*}{ Who } & \multirow[t]{3}{*}{ Identity } & Artefact Based View & 100.00 & 100.00 & 95.00 & 70.00 & 19.33 \\
\hline & & Person Based View & 100.00 & 95.00 & 96.67 & 72.50 & 30.50 \\
\hline & & Total & 100.00 & 93.33 & 92.50 & 76.00 & 27.60 \\
\hline & Authorship & Artefact Based View & 100.00 & 95.00 & 100.00 & 80.00 & 32.00 \\
\hline & History & Total & 94.00 & 96.00 & 94.00 & 84.00 & 25.40 \\
\hline & \multirow[t]{3}{*}{ Total } & Artefact Based View & 100.00 & 96.67 & 97.50 & 74.00 & 24.40 \\
\hline & & Person Based View & 100.00 & 95.00 & 96.67 & 72.50 & 30.50 \\
\hline & & Total & 95.71 & 95.71 & 92.50 & 80.00 & 22.33 \\
\hline \multirow[t]{3}{*}{ When } & Event & Artefact Based View & 100.00 & 90.00 & 93.33 & 92.50 & 19.50 \\
\hline & \multirow[t]{2}{*}{ History } & Person Based View & 100.00 & 60.00 & 80.00 & 40.00 & 25.00 \\
\hline & & Total & 100.00 & 75.00 & 86.67 & 66.25 & 22.25 \\
\hline \multirow[t]{3}{*}{ What } & Action & Artefact Based View & 100.00 & 85.00 & 91.67 & 77.50 & 20.13 \\
\hline & \multirow[t]{2}{*}{ History } & Person Based View & 100.00 & 95.00 & 96.67 & 72.50 & 30.50 \\
\hline & & Total & 100.00 & 86.00 & 92.86 & 77.78 & 25.00 \\
\hline Artefact-Based View & & Total & 100.00 & 88.00 & 92.86 & 77.78 & 17.89 \\
\hline Person-Based View & & Total & 100.00 & 83.33 & 92.50 & 66.00 & 29.40 \\
\hline
\end{tabular}

creating asynchronous awareness for increasingly complex story graphs in relation to the questions who, what, and when, both for the artifact-based view and the person-based view. The exception relating to the person-based view of the question when was measured with a single item. Here, further research is necessary to establish that this exception holds for the visualization of the story graph.

When comparing the mean values of the experimental conditions with each other (see Table 3), we can observe that the mean awareness scores frequently increase from experimental condition 2 to the experimental condition 3. The Mann-Whitney $U$ test (Table 5) showed, however, that these increases are not significant. From an interaction perspective the participants in condition 2 did not need to scroll. However, in condition 3 the participants were required to scroll in order to interact with the whole story graph. Thus, the transition from 'not scrolling' to 'scrolling' had little effect.

Another pattern visible in the mean scores is that the awareness of the participants working with the most complex graph (experimental condition 4) is considerably lower than in the other experimental conditions, particularly compared to the least complex graph (experimental condition 1). The Mann-Whitney U test (Table 5) showed that the differences between conditions 1 and 4 are significant, with the exception of the artifact-based view relating to the question when and the authorship history relating to the question who. 
The exception who/authorship history applies only to the total score, but not to the partial score relating to the artifact-based view. This can be explained by looking at the differences in the multiple-choice questions between these two categories. These questions ask about a summary of the data, e.g. "who is the most active / inactive person?' or 'Who was the last person working on the story graph?'. Considering that the filter mechanisms in combination with the colorcoding allow a quick overview over who changed what, we can conclude that this combination is a suitable mechanism for creating awareness regarding such a summary.

Overall, the awareness levels and usability of the graph visualization (see Figure 11) decreases slightly with increasing complexity. We expected this because graph visualizations usually tend to get confusing the more complex they are. In general, this still shows that the visualization prototype provides the user with all necessary awareness information to get an overview about what happened within a project in the past.

As part of the usability evaluation, the participants provided some feedback for further improvement of the visualization. Some of them mentioned that the color contrast between the age of nodes should be stronger. Also the arrows (edges) should be placed outside the circle and the label on the edges bothered the participants. One of them mentioned to use green color instead of orange for new nodes and edges, because it is more distinguishing. Another improvement would be to create more space between the single nodes and provide in general more screen space for the story graph. The slide bar was not very easy to use. A button for stepwise going through the development of the story graph would be better. Furthermore it would be a nice feature if participants had an actual insight in the visualized audio files with the story graph, e.g. playing the selected part of an audio file by clicking on a specific node.

In addition, the participants requested additional functionality, e.g. highlighting a specific date and a specific user at the same time. Another useful improvement could be to highlight nodes that come from the same audio file, as well as the possibility to move nodes in the visualization and the use of semantic zoom. Finally, as some were not able to see the entire graph while looking at detailed information, they suggested to include an overview map to tackle this issue. The impact of some of these suggestions on the various awareness questions remains an interesting topic for future research.

All in all, the visualization is effective in creating asynchronous awareness for increasingly complex graphs among group members and enables them to trace activities in relation to their story. The results also show that the visualization makes users aware of other users within the story graph and the project. This fact and the easy learning of the story graph handling enables users to track the 
(a) Experimental condition 1

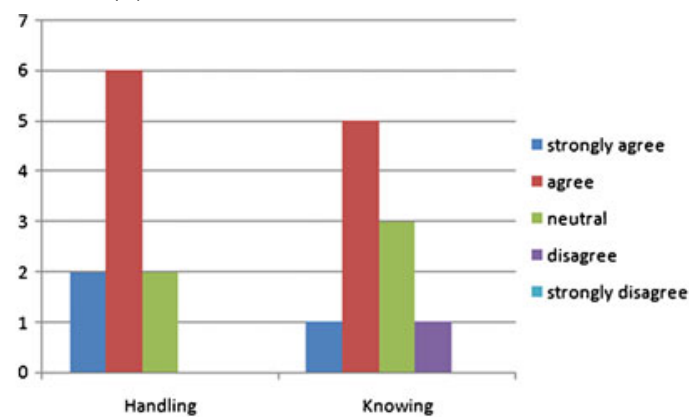

(b) Experimental condition 2

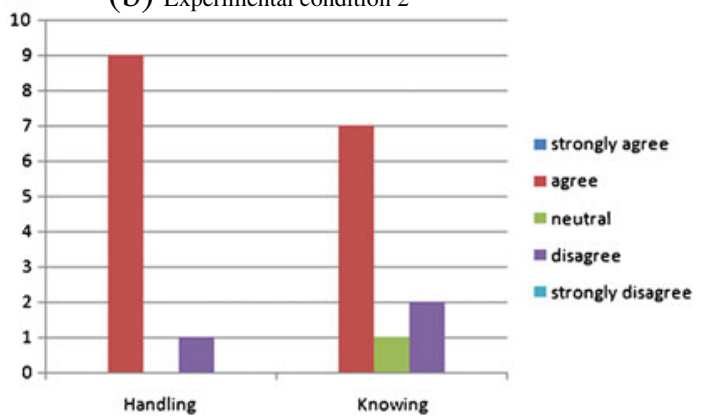

(c) Experimental condition 3

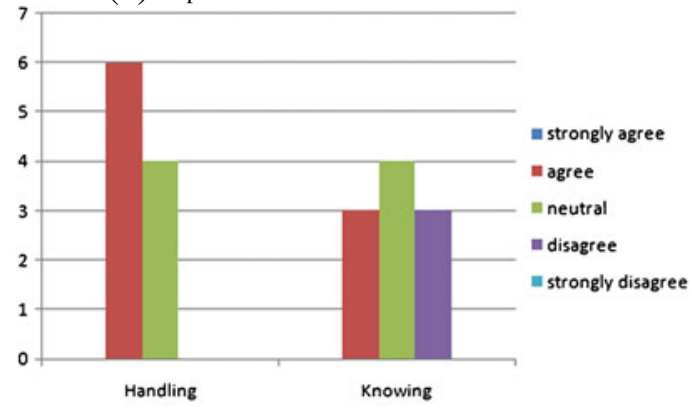

(d) Experimental condition 4

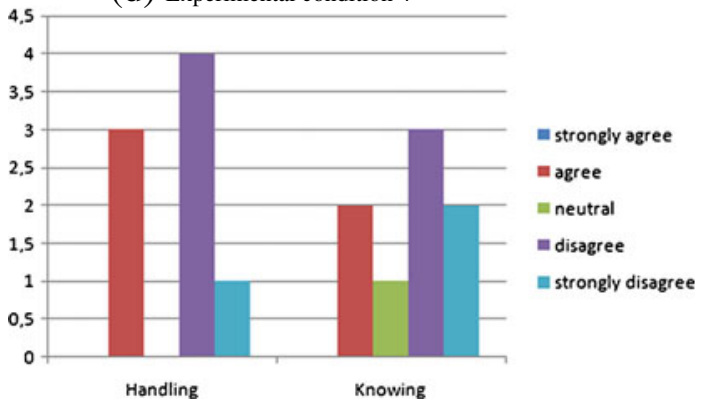

Figure 11. Usability results in the four experimental conditions. 
activities of other users and to question and understand the work results of other users.

\section{Conclusions and future work}

One of the major challenges for collaboration is to achieve shared understanding. When considering asynchronous collaboration, it is essential to provide awareness support that allows users to understand recent changes. Otherwise collaboration can get out of control and missed changes can unintentionally play havoc with the whole collaborative process (Tam and Greenberg 2006).

We have observed the above within CASTing, a tool for collaborative audio-based storytelling (Lukosch et al. 2011). In CASTing, users often collaborate asynchronously and the asynchronously growing story graphs make it difficult for users to trace the evolution of these graphs. Based on the concept of asynchronous workspace awareness (Tam and Greenberg 2006) we identified requirements for a novel approach to visualize the story graph evolution and provide asynchronous awareness support. Our approach focuses on the questions where changes have been made, who has made changes, what changes were made, how things were changed, and when changes did take place. To answer these questions, our approach uses the following key elements:

- The visualization of the story graph evolution and highlights the changes as well as their point in time using different color schemes.

- Tooltips and labels provide users with additional contextual information about nodes and edges in the story graph.

- Different filters allow users aware to identify who has made changes and when changes happened.

- The replay of the story evolution explains how changes were conducted.

We implemented our approach within CASTing and evaluated it in an experiment with 40 participants exploring story graphs of different complexity. The results obtained in this experiment can serve as a baseline comparison for future studies focusing on asynchronous awareness in graphs. We also extended the framework of Tam and Greenberg (Tam and Greenberg 2006) with questions focusing on summaries of the authorship history, e.g. 'Who has been the most active / inactive person working on the story graph?' or 'Who was the last person working on the story graph?'.

Overall, the experiment showed that our visualization approach enables users to acquire awareness by accessing information about previous work of other users and to follow the development process of the story graphs. More specifically, the visualization is effective in creating asynchronous awareness relating to the 
questions who, when, and what, with the exception of when in a person-based view for complex graphs. Another interesting result is that the need to scroll did not have a significant effect on awareness levels, even though it became more difficult for users to navigate in the story graph. Furthermore, for most awareness categories, we could observe a significant decrease in awareness levels when comparing the least complex story graph with the most complex story graph. One notable exception relates to awareness levels regarding summaries of authorship information. Here, awareness levels do not decrease significantly with increasing complexity of the story graph.

The results of the experiment and its limitations also point out several opportunities for further research. First, further research is necessary to overcome the issues in relation with the question when in the person-based view. Second, further research should target the question how awareness support for increasingly complex graphs could look like. Third, the experiment only employed graphs with a regular structure. This regular structure emulates a user's tendency to arrange the nodes in graph to make it easy to gain an overview and thus reduce the complexity of the graph. However, it limits the conclusions we can draw about asynchronous awareness in graphs with a more irregular structure (e.g. graphs that are not planar). In addition, the number of users working on the non-linear story as well as the number of audio files used in the story graph were kept constant during the experiment. Thus, future research could explore how changes in these two variables affect asynchronouns awareness.

During the experiment we also discovered limitations of the prototype which inform future improvements, such as changes to the color coding or additional filters. In addition, users are not able to access the audio files represented by the nodes. While the story graph visualization provides awareness regarding changes to the graph itself, awareness support for the evolution of the underlying content is still missing.

Furthermore, future work should address asynchronous awareness support for the question 'Why were changes made?' (see also Section 1).

In future work, we plan to explore the impact of the suggestions above. Furthermore we plan to address the following questions: Do users require less time to introduce themselves to a project when using our asynchronous awareness support? Does our visualization approach lead to a better coordination and communication between project members? By answering those questions we want to extend our asynchronous awareness support in the future.

Open Access. This article is distributed under the terms of the Creative Commons Attribution License which permits any use, distribution, and reproduction in any medium, provided the original author(s) and the source are credited. 


\section{Appendix}

Table 4. Mean score of items.

\begin{tabular}{|c|c|c|c|c|c|}
\hline Item & Condition 1 & Condition 2 & Condition 3 & Condition 4 & Random Results \\
\hline 1 & 100 & 100 & 100 & 80 & 0 \\
\hline 2 & 100 & 90 & 80 & 90 & 16 \\
\hline 3 & 90 & 90 & 90 & 70 & 25 \\
\hline 4 & 80 & 100 & 80 & 100 & 13 \\
\hline 5 & 100 & 60 & 80 & 40 & 25 \\
\hline 6 & 100 & 100 & 100 & 90 & 25 \\
\hline 7 & 100 & 80 & 90 & 100 & 19 \\
\hline 8 & - & 100 & 90 & 90 & 21 \\
\hline 9 & 100 & 100 & 90 & 60 & 18 \\
\hline 10 & 100 & 90 & 100 & 80 & 64 \\
\hline 11 & - & - & 100 & 90 & 15 \\
\hline 12 & - & - & 100 & 70 & 21 \\
\hline 13 & - & - & - & 90 & 23 \\
\hline 14 & - & - & - & 80 & 19 \\
\hline
\end{tabular}

Table 5. Significance of differences in the means between experimental conditions.

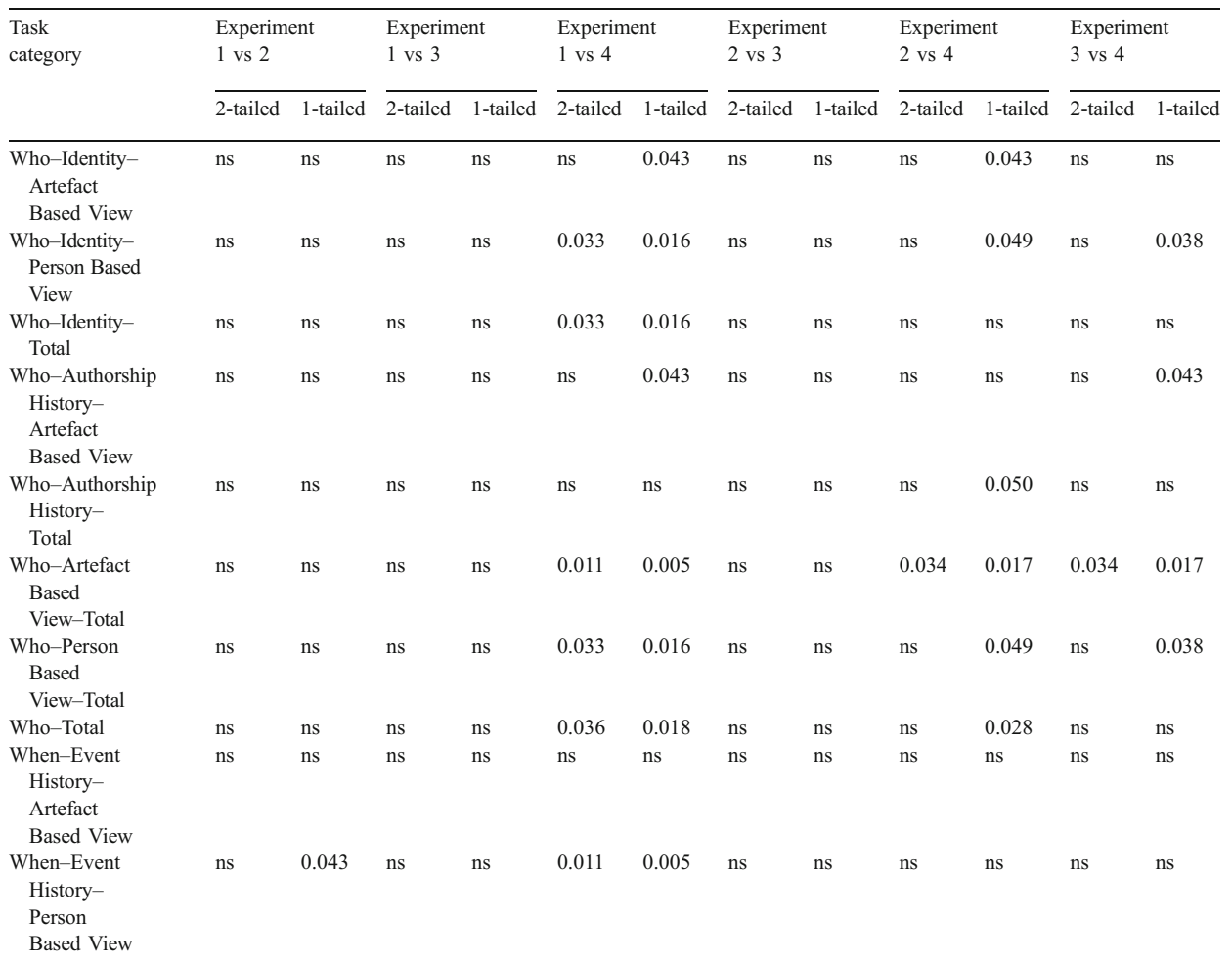


Table 5. (continued).

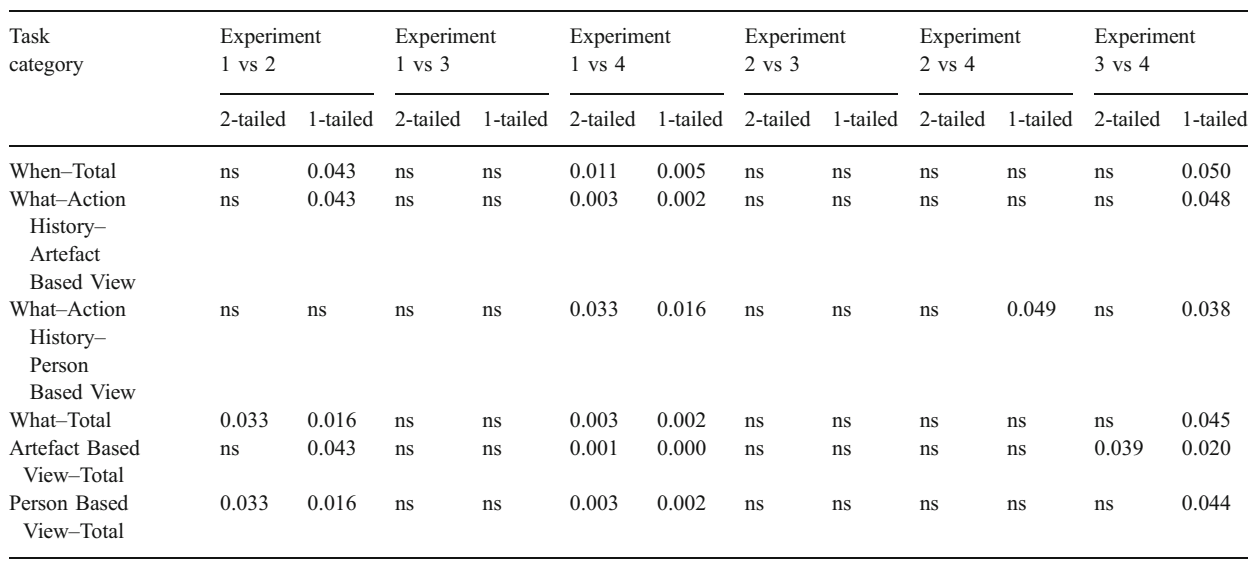

Table 6. Significance of differences in the means of experimental conditions and random results.

\begin{tabular}{|c|c|c|c|c|c|c|c|c|}
\hline \multirow[t]{2}{*}{ Task Category } & \multicolumn{2}{|c|}{ Experiment 1} & \multicolumn{2}{|c|}{ Experiment 2} & \multicolumn{2}{|c|}{ Experiment 3} & \multicolumn{2}{|c|}{ Experiment 4} \\
\hline & 2-tailed & 1-tailed & 2-tailed & 1-tailed & 2-tailed & 1-tailed & 2-tailed & 1-tailed \\
\hline $\begin{array}{l}\text { Who-Identity- } \\
\text { Artefact Based View }\end{array}$ & 0.000 & 0.000 & 0.000 & 0.000 & 0.000 & 0.000 & 0.000 & 0.000 \\
\hline $\begin{array}{l}\text { Who-Identity-Person } \\
\text { Based View }\end{array}$ & 0.000 & 0.000 & 0.000 & 0.000 & 0.000 & 0.000 & 0.000 & 0.000 \\
\hline Who-Identity-Total & 0.000 & 0.000 & 0.000 & 0000 & 0.000 & 0.000 & 0.000 & 0.000 \\
\hline $\begin{array}{c}\text { Who-Authorship } \\
\text { History-Artefact } \\
\text { Based View }\end{array}$ & 0.000 & 0.000 & 0.000 & 0.000 & 0.000 & 0.000 & 0.000 & 0.000 \\
\hline $\begin{array}{l}\text { Who-Authorship } \\
\text { History-Total }\end{array}$ & 0.000 & 0.000 & 0.000 & 0.000 & 0.000 & 0.000 & 0.000 & 0.000 \\
\hline $\begin{array}{l}\text { Who-Artefact Based } \\
\text { View-Total }\end{array}$ & 0.000 & 0.000 & 0.000 & 0000 & 0.000 & 0.000 & 0.000 & 0.000 \\
\hline $\begin{array}{l}\text { Who-Person Based } \\
\text { View-Total }\end{array}$ & 0.000 & 0.000 & 0.000 & 0.000 & 0.000 & 0.000 & 0.000 & 0.000 \\
\hline Who-Total & 0.000 & 0.000 & 0.000 & 0.000 & 0.000 & 0.000 & 0.000 & 0.000 \\
\hline $\begin{array}{c}\text { When-Event History- } \\
\text { Artefact Based View }\end{array}$ & 0.000 & 0.000 & 0.000 & 0.000 & 0.000 & 0.000 & 0.000 & 0.000 \\
\hline $\begin{array}{c}\text { When-Event History- } \\
\text { Person Based View }\end{array}$ & 0.000 & 0.000 & 0.029 & 0.029 & 0.001 & 0.001 & 0.451 & 0.249 \\
\hline When-Total & 0.000 & 0.000 & 0.000 & 0.000 & 0.000 & 0.000 & 0.000 & 0.000 \\
\hline $\begin{array}{l}\text { What-Action History- } \\
\text { Artefact Based View }\end{array}$ & 0.000 & 0.000 & 0.000 & 0.000 & 0.000 & 0.000 & 0.000 & 0.000 \\
\hline $\begin{array}{c}\text { What-Action History- } \\
\text { Person Based View }\end{array}$ & 0.000 & 0.000 & 0.000 & 0.000 & 0.000 & 0.000 & 0.000 & 0.000 \\
\hline
\end{tabular}


Table 6. (continued).

\begin{tabular}{|c|c|c|c|c|c|c|c|c|}
\hline Task Category & 2-tailed & 1-tailed & 2-tailed & 1-tailed & 2-tailed & 1-tailed & 2-tailed & 1-tailed \\
\hline What-Total & 0.000 & 0.000 & 0.000 & 0.000 & 0.000 & 0.000 & 0.000 & 0.000 \\
\hline $\begin{array}{c}\text { Artefact Based } \\
\text { View-Total }\end{array}$ & 0.000 & 0.000 & 0.000 & 0.000 & 0.000 & 0.000 & 0.000 & 0.000 \\
\hline $\begin{array}{c}\text { Person Based } \\
\text { View-Total }\end{array}$ & 0.000 & 0.000 & 0.000 & 0.000 & 0.000 & 0.000 & 0.001 & 0.000 \\
\hline
\end{tabular}

\section{References}

Acosta, Carlos E., Cesar A. Collazos, Luis A. Guerrero, Jose A. Pino, H. Andres Neyem, and Olivier Motelet (2004). Storymapper: A Multimedia Tool to Externalize Knowledge. In G. Navarro (ed): SCCC '04. Proceedings of the XXIV Conference of the Chilean Computer Science Society, Arica, Chile, November 11 to November 12, 2004. Washington, DC: IEEE Computer Society Press, pp. 133-140.

Adobe Systems Incorporated: Open source framework, web application software developmentadobe flex (2011). http://www.adobe.com/de/products/flex/. Accessed 10 May 2011.

Bentley, Richard, Wolfgang Appelt, Uwe Busbach, Elke Hinrichs, D. Kerr, Klaas Sikkel, Jonathan Trevor, and Gerd Woetzel (1997). Basic Support for Cooperative Work on the World Wide Web. International Journal of Human-Computer Studies, Special Issue: Innovative Applications of the World Wide Web, vol. 46, no. 6, pp. 827-846.

Birdeye Group: Birdeye information visualization and visual analytics library (2011). http:// code.google.com/p/birdeye. Accessed 11 May 2011.

Bruner, Jerome (1991). The Narrative Construction of Reality. Critical Inquiry, vol. 18, no. 1, pp. 1-21.

Buttler, Tanja, Stephan G. Lukosch, and Alexander Verbraeck (2011). Frozen Stories - Capturing and Utilizing Frozen Stories for Teaching of Project Managers. In A. Verbraeck, M. Helfert, J. Cordeiro, and B. Shishkov (eds): CSEDU '11. Proceedings of the 3rd International Conference on Computer Supported Education, Noordwijkerhout, The Netherlands, May 6 to May 8, 2011. Lisboa, Portugal: SciTePress- Science and Technology Publications, pp. 120-129.

Carroll, John M., Dennis C. Neale, Philip L. Isenhour, Mary Beth Rosson, and D. Scott McCrickard (2003). Notification and awareness: synchronizing task-oriented collaborative activity. International Journal of Human-Computer Studies, vol. 58, no. 5, pp. 605-632.

Dourish, Paul and Victoria Bellotti (1992). Awareness and coordination in shared workspaces. In M. Mantel and R.M. Baecker (eds): CSCW '92. Proceedings of the Conference on Computer Supported Cooperative Work, Toronto, Canada, October 31 to November 4. New York: ACM Press, pp. 107-114.

Erickson, Thomas, David N. Smith, Wendy A. Kellogg, Mark Laff, John T. Richards, and Erin Bradner (1999). Socially Translucent Systems: Social Proxies, Persistent Conversation, and the Design of "Babble". In M.W. Altom and M.G. Williams (eds): CHI '99. Proceedings of the ACM CHI 99 Human Factors in Computing Systems Conference, Pittsburgh, Pennsylvania, USA, May 15 to May 20, 1999. New York: ACM Press, pp. 72-79.

Facebook Developers. Activity feed (2010). http://developers.facebook.com/docs/reference/plugins/ activity. Accessed 27 July 2011.

Field, Andy P. (2009). Discovering Statistics Using SPSS, 3rd edn., London: SAGE Publications Ltd. 
Friederichs, Thomas and Berthold H. Hass (2006). Der Markt für Hörbücher. Eine Analyse klassischer und neuer Distributionsformen. MedienWirtschaft. Zeitschrift für Medienmanagement und Kommunikationsökonomie, vol. 3, pp. 22-35.

Ganoe, Craig H., Gregorio Convertino, and John M. Carroll (2004). The BRIDGE awareness workspace: tools supporting activity awareness for collaborative project work. In: NordiCHI '03. Proceedings of the Third Nordic Conference on Human-computer Interaction, Tampere, Finland, October 26 to October 27, 2004. New York: ACM Press, pp. 453-454.

Ganoe, Craig H., Jacob P. Somervell, Dennis C. Neale, Philip L. Isenhour, John M. Carroll, Mary Beth Rosson, and D. Scott McCrickard (2003). Classroom BRIDGE: using collaborative public and desktop timelines to support activity awareness. In: UIST '03. Proceedings of the 16th annual ACM symposium on User interface software and technology, Vancouver, Canada, November 2 to November 5, 2003. New York: ACM Press, pp. 21-30.

Gutwin, Carl, Saul Greenberg, and Mark Roseman (1996). Workspace Awareness in Real-Time Distributed Groupware: Framework, Widgets, and Evaluation. In M. Sasse, R. Cunningham, and R. Winder (eds): HCI '96. Proceedings of People and Computers XI, London, UK, August 20 to August 23, 1996. London, UK: Springer-Verlag, pp. 281-298.

Healey, Christopher G. (2010). Perception in Visualization. Department of Computer Science, North Carolina State University. http://www.csc.ncsu.edu/faculty/healey/PP/index.html. Accessed 25 July 2011.

Hein, Gary and Rota Jakuska (2007). Podcast industry. iLabs - Center for Innovation Research, School of Management, University of Michigan-Dearborn.

Lauwers, J. Chris and Keith A. Lantz (1990). Collaboration awareness in support of collaboration transparency: requirements for the next generation of shared window systems. In: CHI '90. Conference on Human Factors in Computing Systems, Special Issue of the SIGCHI Bulletin, Seattle, Washington, USA, April 1 to April 5, 1990. New York: ACM Press, pp. 303-311.

Lu, Stephen C-Y., Waguih ElMaraghy, Günther Schuh, and Robert G. Wilhelm, (2007). A scientific foundation of collaborative engineering. CIRP Annals-Manufacturing Technology, vol. 56, no. 2, 605-634.

Lukosch, Stephan G. (2003). Transparent Latecomer Support for Synchronous Groupware. In J. Favela and D. Decouchant (eds): CRIWG '03. 9th International Workshop on Groupware: Design, Implementation, and Use, Grenoble (Autrans), France, September 28 to October 2, 2003. Berlin Heidelberg: Springer-Verlag, pp. 26-41.

Lukosch, Stephan G. (2004). Transparent and Flexible Data Sharing for Synchronous Groupware. International Journal of Computer Applications in Technology, Special Issue: Current Approaches for Groupware Design, Implementation and Evaluation, vol. 19, nos. 3/4, pp. 215-230.

Lukosch, Stephan G., Michael Klebl, and Tanja Buttler (2008). Facilitating audio-based collaborative storytelling for informal knowledge management. In R.O. Briggs, P. Antunes, and G.J.d. Vreede (eds): CRIWG '08. Proceedings of the 14th Collaboration Researchers' International Workshop on Groupware, Omaha, US, September 14 to September 18, 2008. Berlin Heidelberg: Springer-Verlag, pp. 289-304.

Lukosch, Stephpan G., Michael Klebl, and Tanja Buttler (2011). Utilizing Verbally Told Stories for Informal Knowledge Management. Group Decision and Negotiation Journal, Special Issue on the 14th Collaboration Researchers International Workshop on Groupware, vol. 20, no. 5, pp. 615-642.

Martens, Dirk and Rolf Amann (2007). Podcast: Wear-out oder Habitualisierung? Media Perspektiven, vol. 11, pp. 538-551.

Nunamaker Jr., Jay F., Bruce A. Reinig, and Robert O. Briggs (2009). Principles for effective virtual teamwork. Communications of the ACM, vol. 52, no. 4, pp. 113-117. 
Nunamaker Jr., Jay F., Robert O. Briggs, Daniel D. Mittleman, Douglas R. Vogel, and Pierre A. Balthazard (1997). Lessons From a Dozen Years of Group Support Systems Research: A Discussion of Lab and Field Findings. Journal of Management Information Systems, vol. 13, pp. 163-207.

Ochs, Elinor and Lisa Capps (2001). Living Narrative: Creating Lives in Everyday Storytelling. Cambridge, Massachusetts: Harvard University Press.

Orr, Julian E. (1996). Talking About Machines: An Ethnography of a Modern Job. Ithaca, New York: Cornell University Press.

Pankoke-Babatz, Uta, Wolfgang Prinz, and Leonie Schäfer (2004). Stories About Asynchronous Awareness. In F. Darses, R. Dieng, C. Simone, and M. Zacklad (eds): Cooperative Systems Design-Scenario-Based Design of Collaborative Systems, Hyères Les Palmiers, France, May 11 to May 14, 2004. Amsterdam: IOS Press, pp. 23-38.

Perret, Raphael, Marcos R.S. Borges, and Flávia Maria Santoro (2004). Applying Group Storytelling in Knowledge Management. In G.-J. de Vreede, L.A. Guerrero, and G.M. Raventós (eds): CRIWG '04. 10th International Workshop on Groupware: Design, Implementation and Use, San Carlos, Costa Rica, September 5 to September 9, 2004. Berlin Heidelberg: SpringerVerlag, pp. 34-41.

Philips, Deborah (2007). Talking Books: The Encounter of Literature and Technology in the Audio Book. Convergence, vol. 13, no. 3, pp. 293-306.

Piirainen, Kalle, Gwendolyn Kolfschoten, and Stephan G. Lukosch (2010). In Search For The Right Tools to Fix the Right Problem: A Look into the Challenges of Collaborative Design. In R.H. Sprague Jr. (ed): HICSS '43. Hawaii International Conference on System Sciences, Poipu, Kauai, Hawaii, January 5 to January 8, 2010. Washington, DC: IEEE Computer Society Press, pp. 1-10.

Röber, Niklas, Cornelius Huber, Knut Hartmann, Matthias Feustel, and Maic Masuch (2006). Interactive Audiobooks: Combining Narratives with Game Elements. In S. Göbel, R. Malkewitz, and I. Iurgel (eds): TIDSE '06. Third International Conference on Technologies for Interactive Digital Storytelling and Entertainment, Darmstadt, Germany, December 4 to December 6, 2006. Berlin Heidelberg: Springer-Verlag, pp. 358-369.

Santoro, Flávia Maria, Marcos R.S. Borges, and Jose A. Pino (2010). Acquiring knowledge on business processes from stakeholders' stories. Advanced Engineering Informatics, vol. 24, no. 2, pp. 138-148.

Schäfer, Leonie, Carla Valle, and Wolfgang Prinz (2004). Group storytelling for team awareness and entertainment. In: NordiCHI '03. Proceedings of the 3rd Nordic Conference on HumanComputer Interaction, Tampere, Finland, October 23 to October 27, 2004. New York: ACM Press, pp. 441-444.

Schümmer, Till and Stephan G. Lukosch (2007). Patterns for Computer-Mediated Interaction. Chichester: John Wiley \& Sons.

Spaniol, Marc, Ralf Klamma, Nalin Sharda, and Matthias Jarke (2006). Web-Based Learning with Non-linear Multimedia Stories. In W. Liu, Q. Li, and R.W.H. Lau (eds): ICWL '06. 5th International Conference on Advances in Web Based Learning, Penang, Malaysia, July 19 to July 21, 2006. Berlin Heidelberg: Springer-Verlag, pp. 249-263.

Tam, James and Saul Greenberg (2006). A Framework for Asynchronous Change Awareness in Collaborative Documents and Workspaces. International Journal of Human-Computer Studies, vol. 64 , no. 7 , pp. 583-598.

Totzke, Rainer (2005). Erinnern-Erzählen-Wissen-Was haben (Erfahrungs-) Geschichten mit echtem Wissen zu tun? In G.E. Reinmann (ed.): Erfahrungswissen erzählbar machen—narrative Ansätze für Wirtschaft und Schule. Lengerich: Pabst Science Publications, pp. 19-35.

Valle, Carla, Elaine M. Raybourn, Wolfgang Prinz, and Marcos R.S. Borges (2003). Group Storytelling to Support Tacit Knowledge Externalization. In C. Stephanidis (ed): HCII '03. 
Proceedings of the 10th International Conference on Human-Computer Interaction, Crete, Greece, June 22 to June 27, 2003. Mahwah, New York: Lawrence Erlbaum Associates, Inc, pp. $1218-1222$.

VoiceThread LLC: Voicethread-group conversations around images, documents, and videos (2011). http://voicethread.com/. Accessed 10 June 2011.

Weick, Karl E., Kathleen M. Sutcliffe, and David Obstfeld (2005). Organizing and the Process of Sensemaking. Organization Science, vol. 16, no. 4, pp. 409-421.

Wikipedia: Wiki-Wikipedia, The Free Encyclopedia (2011). http://en.wikipedia.org/w/index.php? title=Wiki\&oldid=369908312. Accessed 13 June 2011. 